\title{
Identity Fusion, Outgroup Relations, and Sacrifice: A Cross-Cultural Test
}

\author{
Benjamin Grant Purzycki \\ Max Planck Institute for Evolutionary Anthropology
}

\author{
Martin Lang \\ Harvard University, Masaryk University
}

\begin{abstract}
Identify fusion theory has become a popular psychological explanation of costly self-sacrifice. It posits that while maintaining one's own individual identity, a deep affinity with one's group can contribute to sacrifice for that group. We test this and related hypotheses using a behavioral economic experiment designed to detect biased, self-interested favoritism among eight different populations ranging from foragers and horticulturalists to the fully market-integrated. We find that while individuals favor themselves on average, those with higher ingroup fusion sacrifice more money to other members of their ingroup who are unlikely to reciprocate. We also find that positive outgroup relations also has a similar effect. Additionally, as outgroup relations vary considerably across our subsamples, we assess a recently-posited interaction between ingroup and outgroup relations. This interaction shows no consistent effect at the individual or sub-sample levels.
\end{abstract}

Keywords: identity fusion, cooperation, sacrifice, intergroup dynamics

The theory of identity fusion (Swann, et al., 2015; 2009; $2010 \mathrm{~b} ; 2014 \mathrm{a}$ ) has received a considerable attention for its ability to predict self-expressed willingness to sacrifice for a group. The visceral feeling of oneness blurs the boundaries between individuals, fostering close affinity with each other. In contrast to social identity theory (Tajfel and Turner, 1979), fused individuals' identities are not dissolved by group identity. Rather, because personal and social identities are functionally equivalent, the retention of personal identity while fused motivates people to engage in costly pro-group behavior (Swann, et al., 2010b; Swann, et al., 2012). Recently, Whitehouse (2018) articulated a chain of events where perceived sharedness with groups leads to local fusion whichinteracting with outgroup threats-predicts sacrifice.

Empirical support for the theory is growing. In studies using the trolley dilemma, fused Spaniards expressed higher willingness to self-sacrifice in order to save other Spaniards than their less-fused counterparts (Swann, et al., 2010a). Fused individuals are more likely to claim they are willing to fight and die for their country (Swann, et al., 2010a; Swann, et al., 2014a; Swann, et al., 2014b; Whitehouse, et al., 2017). Evidence from Iraq (Gómez, et al., 2017) and Libya (Whitehouse, et al., 2014) shows that fusion with a fighting band creates strong "brother-like" relationships that are more important than family ties, especially when defending the group's sacred values. Further evidence exists from Morocco and Spain where highly-fused individuals are more likely to claim support for costly sacrifices devoted to jihad and democracy, respectively (Sheikh, Gómez, and Atran, 2016).

As it was originally conceived to explain "extreme" be- haviors, the bulk of the research focuses on very costly acts of self-sacrifice. If we assume that "extreme" sacrifice is on one end of a distribution of costs, it follows that the theory should cover subtler forms of sacrifice. Indeed, some studies suggest this is the case (e.g., Swann, et al., 2010b). However, as a consequence of focusing on extreme behavior, some of this work (Swann, et al., 2009; 2010a) dichotomizes fusion scales, thus treating fusion and costs of self-sacrifice as traitlike characteristics rather than continuous covariates lying on a spectrum (cf. Gómez, et al., 2011; Jiminez, et al., 2016; Segal, Jong, and Halberstadt, in press; Swann, et al., 2010b). Moreover, the bulk of the literature considers self-reports of willingness to engage in or support of others' extreme acts rather than actual behaviors. Importantly, this research has largely bypassed sampling from traditional, non-state societies (cf. Swann, et al., 2014a).

Here, we examine whether or not identity fusion, intergroup relations, and perceived cultural similarity facilitate costly, sacrificial behavior across eight culturally diverse field sites. By considering foregoing self-interested gains through fair impartiality toward members of one's ethnicreligious group as a relatively subtle form of self-sacrifice, we examine whether or not perceive cultural similarity as well as intergroup relations predict sacrificing money for one's group.

\section{Method}

To assess the role fusion and intergroup relations plays on sacrifice, we utilize the Evolution of Religion and Morality Project dataset (Purzycki, et al., 2016a) that includes data ( $N$ $=592$ ) from eight ethnographically unique field sites (Ta- 


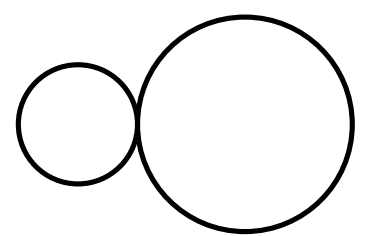

Self Other

1

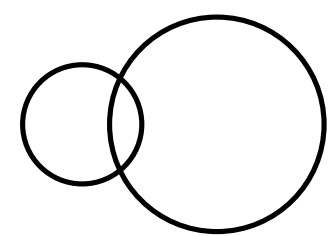

Self

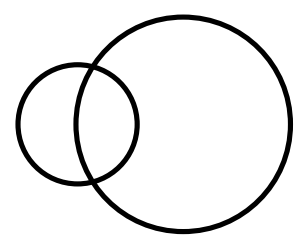

Self Other

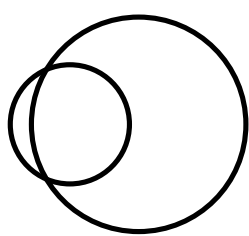

Self Other

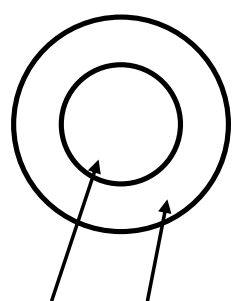

Self Other

3

Figure 1. Pictorial scale for group relations. Scale modified from Swann, et al. (2009) which was adapted from Schubert and Otten (2002). See supplements for question definitions.

ble 1) that cover a diverse range of human societies. Our sample includes Hadza foragers from Tanzania, horticulturalist inland populations from Tanna, Vanuatu, a more marketintegrated coastal sample from the same island, Indo- and native Fijians, Tyvans from Siberia, Brazilians from Marajó island, and residents of Porte aux Piment, Mauritius. See Purzycki, et al. (2016a) and Table 1 for further details of each sub-sample.

Sacrifice. We measure sacrifice with outcomes in a Random Allocation Game (Hruschka, et al., 2014; Jiang, 2013; Purzycki, et al., 2016b). In this experiment, participants have two cups designated for specific recipients, a fair, twocolored die, and 30 coins. They are supposed to think of which cup they would like to put a coin into and roll the die. If the die comes up one color, they get to put the coin into the cup of which they thought. If it comes up the other color, they put the coin into the opposite cup. Regardless of their thoughts or the die roll, the outcome should be random with any given coin having a 50\% chance of going to either cup and therefore follow a binomial distribution. However, as participants play alone, they can break the rules and favor one cup over the other. If aggregate allocations deviate from a binomial distribution, this is indicative of systematic, rulebreaking favoritism.

In the game reported here, cups were designated for participants and a co-ethnic, co-religionist from a geographically distant community. In addition to their show-up fees ( $\sim 10 \%$ a day's wage), participants kept the coins that landed in their cups and researchers distributed the money from the other cup to randomly selected geographically distant individuals. Participants stood to gain from cheating; they played alone and could put more coins into their own cup (30 coins amounted to roughly half a day's average wage in the local economy). Considering all allocations not in their own cups were going to other people not capable of reciprocating, playing fairly (or generously) meant actually sacrificing potential gains with virtually no chance of a return.

Intergroup relations. We measured individuals' relation- ships with various groups using a standard visual fusion scale (Schubert and Otten, 2002; Swann, et al., 2009, Figure 1). This had the benefit of being comparable across samples that vary in numeracy and literacy. Participants pointed to the image ( 1 to 5 ; low to high) best representing how emotionally close they were to: (1) their ingroups, (2) geographically distant co-ethnic, co-religionists, and (3) geographically distant ethnic/religious outgroups ${ }^{1}$. We defined outgroups as "a stranger, non-co-religionist living in a distant (but known) place." Note that relationships with outgroups inevitably varied across sites (e.g., some intergroup relations were indifferent whereas other groups had long-standing and often violent feuds). We also asked how similar participants thought the distant recipients' religious traditions were ( -2 to 2$)$. See Table 1 for group-level values of these scales.

Hypotheses. If ingroup fusion leads to self-sacrifice, participants with higher ratings of ingroup emotional closeness should be more likely to sacrifice money to distant ingroups. Similarly, increased reported religious similarity to recipients ought to decrease the chances of players keeping more coins for themselves. Finally, to the extent that low outgroup relations scores indicate hostility, we should expect an interaction effect between ingroup fusion and outgroup relations where low outgroup scores and high ingroup fusion scores should predict sacrificing coins.

\section{Model}

Here, we: (a) formalize a set of theoretically-focused models that (b) allows the proposed predictors and their interaction to vary across sites (c) in a Bayesian statistical framework that (d) monotonically models scales' effects. We restrict the bulk of our discussion here to four focal model

\footnotetext{
${ }^{1}$ While the visual component of the scale was the same across target groups, we reserve using the term "fusion" for only the ingroup measure and characterize the measure for other groups as "relations" for the sake of presentation. See discussion and supplements for further elaboration.
} 
Table 1

Descriptive features of target variables for each field site.

\begin{tabular}{ccc|cc|c|c}
\hline $\mathbf{N}$ & Site/Ingroup & Fusion & Outgroup & Fusion & Coins to Self & References \\
\hline 42 & Christian Coastal Tannese & $4.05(1.27)$ & Noumeans & $1.74(1.34)$ & $15.32(2.51)$ & Atkinson (2018) \\
67 & Hadza (regional) & $4.71(0.79)$ & Datoga & $1.79(1.27)$ & $17.82(4.31)$ & Apicella (2018) \\
73 & Kastom Inland Tannese & $4.56(0.85)$ & Noumeans & $2.42(1.87)$ & $15.93(3.80)$ & Atkinson (2018) \\
75 & Hindu Indo-Fijians & $3.53(1.47)$ & Muslim Indo-Fijians & $3.07(1.56)$ & $15.07(2.96)$ & Willard (2018) \\
65 & Marajó Brazilians* & $3.96(1.42)$ & Evang./Cathol. & $2.22(1.58)$ & $15.43(3.74)$ & Cohen, Baimel, and Purzycki (2018) \\
95 & Hindu Mauritians & $4.38(0.92)$ & Muslim Mauritians & $2.28(1.40)$ & $16.30(3.32)$ & Xygalatas, et al. (2018) \\
79 & Buddhist Tyvans & $3.77(1.47)$ & Christian Russians & $2.25(1.47)$ & $14.70(2.95)$ & Purzycki and Kulundary (2018) \\
73 & Yasawan-Fijians & $1.99(0.26)$ & Indo-Fijians & $1.01(0.12)$ & $18.39(4.98)$ & McNamara and Henrich (2018) \\
\hline
\end{tabular}

Note. Values are means (standard deviations). *When participants were Catholic, the Ingroup and Distant was Catholic while the Outgroup was Evangelical (and vice versa). See Purzycki, et al. (2018) and references above for further details and analysis.

specifications (see supplemental for more and further discussion).

We define our four focal models below (see supplements for further model specifications). Model 1 includes only the effect of ingroup fusion on allocations. Model 2 assesses the effect of outgroup relations. Model 3 includes the interaction between ingroup and outgroup scores, and Model 4 is the full model that includes ingroup fusion, outgroup relations, their interaction, and the religious similarity score ${ }^{2}$.

$$
y_{i} \sim \operatorname{Binomial}\left(30, p_{i}\right)
$$

Model 1: $\operatorname{logit}\left(p_{i}\right)=\alpha_{S_{(i)}}+\beta_{S_{(i)}} g_{i}$

Model 2: $\operatorname{logit}\left(p_{i}\right)=\alpha_{S_{(i)}}+\beta_{S_{(i)}} o_{i}$

Model 3: $\operatorname{logit}\left(p_{i}\right)=\alpha_{S_{(i)}}+\beta_{S_{(i)}} g_{i}+\gamma_{S_{(i)}} o_{i}+\psi_{S_{(i)}} g_{i} o_{i}$ Model 4: $\operatorname{logit}\left(p_{i}\right)=\alpha_{S_{(i)}}+\beta_{S_{(i)}} g_{i}+\gamma_{S_{(i)}} o_{i}+\psi_{S_{(i)}} g_{i} o_{i}+\delta_{S_{(i)}} r_{i}$

$$
\begin{aligned}
{\left[\begin{array}{l}
\alpha_{s} \\
\beta_{s} \\
\gamma_{s} \\
\psi_{s} \\
\delta_{s}
\end{array}\right] \sim \operatorname{Multivariate} \operatorname{Normal}(\mu, \mathbf{S R S}) } \\
\mathbf{S}= \\
{\left[\begin{array}{ccccc}
\sigma_{\alpha} & 0 & 0 & 0 & 0 \\
0 & \sigma_{\beta} & 0 & 0 & 0 \\
0 & 0 & \sigma_{\gamma} & 0 & 0 \\
0 & 0 & 0 & \sigma_{\psi} & 0 \\
0 & 0 & 0 & 0 & \sigma_{\delta}
\end{array}\right] } \\
\sigma_{p} \sim \operatorname{Cauchy}(0,2) \\
\mu_{p} \sim \operatorname{Normal}(0,1) \\
\mathbf{R} \sim \operatorname{LKJCorr}(4)
\end{aligned}
$$

We model the coin allocations $y_{i}$ out of 30 using a binomial logistic regression with a logit link (note that the formal model includes all priors and diagonal matrix for Model 4 parameters for the sake of illustrating the full model). The variables are as follows: $g_{i}$ denotes individuals' ingroup fusion score, $o_{i}$ is their outgroup score, $g_{i} o_{i}$ represents the interaction between the two, and $r_{i}$ is the religious similarity score.
The subscripts $i$ and $s$ denote individual and field site respectively and $S(i)$ is a function returning the site index of individual $i$. Each field site gets its own intercept, $\alpha_{s}$, and slope for ingroup and outgroup relations $\left(\beta_{s}\right.$ and $\gamma_{s}$, respectively), their interaction, $\psi_{s}$, and/or religious similarlity, $\delta_{s}$. These parameters are assigned a prior distribution defined by their respective mean vector $\mu$ and covariance matrix SRS. S is a diagonal matrix of each parameter's standard deviation, $\sigma_{p}$, and $\mathbf{R}$ is the correlation matrix. $\mathbf{R}$ is assigned a weakly regularizing prior from the LKJCorr family (Lewandowski, et al., 2009) where $\eta=4$. Note that the formal definitions above include all parameters for illustration (i.e., it follows Model 4, the full model). These models are implemented using non-centered parameterization. As scales' values were ordered categorical, we modelled their effects monotonically using the brms package (Bürkner, 2017) for R. Across the specifications reported here, the model sampled quite well (all $\hat{R}=1.00$ and all effective sample sizes were quite large).

\section{Results}

Figure 2 illustrates the results across four model specifications (see supplemental for results tables). Across all models, the main intercept's credibility interval is entirely $<0$. We can therefore confidently state that on average, individuals favored their own cups. There is also some notable crosscultural variation. For example, Tyvan, Coastal Tannese, and Lovu participants tended to sacrifice more coins while the Hadza and Yasawan-Fijians tended to favor themselves.

Ingroup fusion predicted sacrifice. The ingroup fusion model (Model 1) predicts a $45 \%(\mathrm{CI}=[40-49 \%])$ chance of sacrificing a coin, holding all other factors constant. It shows that extreme ingroup fusion (i.e., a value of 5) increases the chances of sacrificing a coin to $56 \%$. Note, too, the crosscultural variation; being from Mauritius shows that higher values of ingroup fusion predict more self-favoritism while the direction of the effect is reversed for Brazilians.

\footnotetext{
${ }^{2}$ Note that the Hadza did not answer questions about religious similarity. They are therefore dropped from Model 4.
} 
As shown in Model 2, the outgroup relations measure also predicted sacrificing more money to distant ingroup members. This model predicts an $8 \%$ increase in the probability of an individual sacrificing a coin when outgroup relations scores are at their maxiumum. Moreover, this measure had different effects across sites. This implies that values of the outgroup relations scale took on different meanings. Among the Coastal Tannese and Hadza samples, for example, higher outgroup scores predicted more withholding while the Mauritians and Brazilian samples were more likely to sacrifice coins to distant ingroup members when outgroup scores were higher.

Model 3 includes individual (denoted by "Ingroup*Outgroup" in the figure) and site-specific (denoted by " $g * o$ ") effects of the ingroup-outgroup interaction. Holding all other factors constant, the probability of sacrificing a coin (i.e., the logistic transform of the main intercept) is $44 \%$, CI $=[40-49 \%]$. The interaction has virtually no association with sacrifice at the individual level. Site-specific estimates of the interaction varied slightly, but overall, individuals in any context are no more likely to sacrifice coins because of the interaction between ingroup and outgroup relations. Model 4 includes perceived religious similarity to distant players. Holding all other factors constant, the model predicts that religious similarity of distant recipients increases the predicted sacrifice probability by an additional $2 \%$ per scale unit.

\section{Discussion}

We confirm here that ingroup fusion can help account for actual behaviors with cost-benefit consequences subtler than extreme self-sacrifice (Swann, et al., 2010a; Whitehouse, 2018). Importantly, we also show that the magnitude of the effect of an individual's relations with various groups varies cross-culturally.

While ingroup fusion predicted sacrifice, the effect was not large. Similarly, perceived religious similarity of recipients and outgroup relations showed positive-but-slight associations with sacrifice. These mild associations might be due in part to the fact that game rules anchor the experiment's outcome around a binomial distribution; the signal from fusion might be clearer using another game that is free from such constraints (e.g., the dictator game).

We also found a similar effect for outgroup relations. This raises the distinct possibility that this often-used pictorial fusion scale measures general prosociality rather than fusion per se. Given how robust its association with sacrifice is across contexts and studies, coupled with the fact that the same measure for outgroups predicted sacrifice for distant ingroups, it serves as an important reminder that multiple methods and attention to contextual details of intergroup relations is necessary to rule out what exactly this measure assesses.
We found no support for the recently proposed (Whitehouse, 2018) interaction of ingroup and outgroup relations on sacrifice (see supplementary section 3.4.2 for an assessment of the extreme cases). This is likely due to the outgroup measure; we did not directly ask about negative attitudes towards outgroups. Furthermore, a signal of the effect may have been clearer in a similar experiment where participants can directly benefit their local group-rather than distant ingroup members-at a cost to themselves. Tyvans played one such game with a self-local community dyad (see supplements) but the interaction had no obvious effect. However, they did show a greater likelihood of giving coins to themselves as fusion increased. Yet, given that they largely played by the rules and the cross-cultural variation we reported above, it remains unlikely that this effect would be consistent across contexts.

It is also possible that the selected outgroup relations across the entire sample lacked sufficient variability-or too much in the meaning of low scores of outgroup relations-to detect an interaction effect. First, recall that there was considerable variation in outgroup ratings across sites. As our modelling structure allows such effects to vary across sites, by implication, cross-cultural differences in the meaning of outgroup relationships are partially accounted for. Indeed, that we found that the effect of the outgroup relations measure varied across sites; cross-culturally, ratings of outgroup relations were differentially associated with gameplay. If individuals in two different field sites had very low ratings for outgroups and these low ratings indicate hostility for one and no relationship for another, the model allows by-site increases in these values to have differential effects on outcome within those sites.

Curiously, in the case of the Hadza who have a longstanding territorial feud with the Datoga and a history of sporadic lethal conflict (Marlowe, 2010), larger outgroup relations scores predicted keeping coins, not sacrificing them. It is possible that because the Datoga and their herds are encroaching on Hadza territory, the overlapping circles may have been interpreted as negative-i.e., a metaphor for Hadza being incorporated into Datoga lifeways and territory rather than emotional proximity. In other words, the closer Hadza think the Datoga are, the more inclined they are to keep more money from geographically distant Hadza. If so, the fusion measure might be too reliant on a spatial metaphor that is neither universal nor indicative of the same social phenomena for a similarly diverse sample. In addition to having the prequisite knowledge of participants' lifeways, having a better sense of how participants interpret the scale would rule out such possibilities.

Further research with more diverse intergroup relations, nuanced, and more direct measures for outgroup relations would nevertheless provide more confidence in inferencemaking, particularly with respect to how much "fusion"- 
above and beyond general sociability-contributes to sacrificial behaviors across the cost spectrum and societies.

\section{Acknowledgments}

We thank the Cultural Evolution of Religion Research Consortium (CERC) for making this project possible and the Department of Human Behavior, Ecology, and Culture at the Max Planck Institute for Evolutionary Anthropology for their feedback. We thank Harvey Whitehouse for suggesting we include the fusion questions during the early planning stages of the Evolution of Religion and Morality Project, and his thoughts on an earlier draft of this manuscript. We also thank Ángel Gómez, Jonathan Jong, Chris Kavanagh, Radek Kundt, and Justin Lane as well for their comments on earlier drafts.

\section{Supplemental Material}

Supplementary analyses and all materials used here are available at http://github.com/bgpurzycki/fusion.

\section{Ethical Statement}

This project was originally approved by the University of British Columbia's Behavioural Research Ethics Board (\#H13-00671) and subsequently approved by the ethical review boards at the home university of each researcher who collected the data.

\section{Author Contributions}

B.G.P. initiated and managed this project, wrote the bulk of the main text, conducted the main analyses, and contributed to the supplementary materials. M.L. contributed to writing the main text and wrote the bulk of the supplementary materials.

\section{Declaration of Conflicting Interests}

The authors declare that they have no conflicts of interest with respect to the authorship or publication of this article.

\section{Funding}

CERC was supported by a SSHRC partnership grant (\#8952011-1009) and the John Templeton Foundation (grant ID 40603). BGP acknowledges support from the Max Planck Institute for Evolutionary Anthropology and ML acknowledges funding by the Laboratory for the Experimental Research of Religion [CZ.1.07/2.3.00/20.048] and the Czech Science Foundation (GA CR) [18-18316S].

\section{Open Practices}

We used the publicly available Evolution of Religion and Morality Project data set (Purzycki, et al., 2016a, Version 5.0). All data and analytical scripts for use in $\mathrm{R}$ are available at http://github.com/bgpurzycki/fusion.

\section{References}

Apicella, C. L., 2018. High levels of rule-bending in a minimally religious and largely egalitarian forager population. Religion, Brain and Behavior, 8(2), 133-148.

Atkinson, Q. D., 2018. Religion and expanding the cooperative sphere in Kastom and Christian villages on Tanna, Vanuatu. Religion, Brain and Behavior, 8(2), 149-167.

Bürkner, P. C., 2017. brms: An R package for Bayesian multilevel models using Stan. Journal of Statistical Software, 80(1), 128.

Cohen, E., Baimel, A., Purzycki, B. G., 2018. Religiosity and resource allocation in Marajó, Brazil. Religion, Brain and Behavior, 8(2), 168-184.

Gómez, Á., Brooks, M. L., Buhrmester, M.D., Vázquez, A., Jetten, J., and Swann Jr., W. B., 2011. On the nature of identity fusion: Insights into the construct and a new measure. Journal of Personality and Social Psychology, 100(5), 918-933.

Gómez, Á., López-Rodríguez, L., Sheikh, H., Ginges, J., Wilson, L., Waziri, H., Vázquez, A., Davis, R., and Atran, S., 2017. The devoted actor's will to fight and the spiritual dimension of human conflict. Nature Human Behaviour, 1(9), 673-679.

Hruschka, D., Efferson, C., Jiang, T., Falletta-Cowden, A., Sigurdsson, S., McNamara, R., Sands, M., Munira, S., Slingerland, E., and Henrich, J., 2014. Impartial institutions, pathogen stress and the expanding social network. Human Nature, 25(4), 567-579.

Jiang, T. Cheating in mind games: The subtlety of rules matters. Journal of Economic Behavior and Organization, 93(9), 328-336.

Jiminez, J. and Gómez, A., Buhrmester, M.D., and Vázquez, A. and Whitehouse, H., and Swann, W. The dynamic identity fusion index: A new continuous measure of identity fusion for web-based questionnaires. Social Science Computer Review, 34(2), 215-228.

Lewandowski, D., Kurowicka, D., Joe, H., 2009. Generating random correlation matrices based on vines and extended onion method. Journal of Multivariate Analysis, 100(9), 19892001.

Marlowe, F., 2010. The Hadza: Hunter-Gatherers of Tanzania. Berkeley: University of California Press.

McNamara, R. A., Henrich, J., 2018. Jesus vs. the ancestors: how specific religious beliefs shape prosociality on Yasawa Island, Fiji. Religion, Brain and Behavior, 8(2), 185-204.

Purzycki, B. G., Apicella, C., Atkinson, Q. D., Cohen, E., McNamara, R. A., Willard, A. K., Xygalatas, D., Norenzayan, A., Henrich, J., 2016. Cross-cultural dataset for the evolution of religion and morality project. Scientific Data, 3, 160099.

Purzycki, B. G., Apicella, C., Atkinson, Q. D., Cohen, E., McNamara, R. A., Willard, A. K., Xygalatas, D., Norenzayan, A., Henrich, J., 2016b. Moralistic gods, supernatural 
punishment and the expansion of human sociality. Nature, 530(7590), 327-330.

Purzycki, B. G., Kulundary, V., 2018. Buddhism, identity, and class: fairness and favoritism in the Tyva Republic. Religion, Brain and Behavior, 8(2), 205-226.

Purzycki, B. G., Norenzayan, A., Apicella, C., Atkinson, Q. D., Cohen, E., Henrich, J., McNamara, R. A., Willard, A. K., Xygalatas, D., 2018. The evolution of religion and morality: A synthesis of ethnographic and experimental evidence from eight societies. Religion, Brain and Behavior, 8(2), 101-132.

Schubert, T. W., Otten, S., 2002. Overlap of self, ingroup, and outgroup: Pictorial measures of self-categorization. Self and Identity, 1(4), 353-376.

Segal, K., Jong, J., and Halberstadt, J., in press. The fusing power of natural disasters: An experimental study. Self and Identity.

Sheikh, H., Gómez, Á., Atran, S., 2012. Empirical evidence for the devoted actor model. Current Anthropology, 57(S13), S204S209.

Swann Jr., W. B., Buhrmester, M. D. Identity fusion. Current Directions in Psychological Science, 24(1), 52-57.

Swann Jr., W. B., Gómez, Á., Seyle, D. C., Morales, J., Huici, C., 2009. Identity fusion: The interplay of personal and social identities in extreme group behavior. Journal of Personality and Social Psychology, 96(5), 995-1011.

Swann Jr., W. B., Gómez, Á., Dovidio, J., Hart, S., and Jetten, J., 2010a. Dying and killing for one's group: Identity fusion moderates responses to intergroup versions of the trolley problem. Psychological Science, 21(8), 1176-1183.

Swann Jr., W. B., Gómez, A., Huici, C., Morales, J., and Hixon, J. G., 2010b. Identity fusion and self-sacrifice: Arousal as a catalyst of pro-group fighting, dying, and helping behavior. Journal of Personality and Social Psychology, 99(5), 824841.

Swann Jr., W. B., Jetten, J., Gómez, Á., Whitehouse, H., and Bastian, B., 2012. When group membership gets personal: a theory of identity fusion. Psychological Review, 119(3), 441456.

Swann Jr., W. B., Buhrmester, M. D., Gómez, A., Jetten, J., Bastian, B., Vázquez, A., Ariyanto, A., Besta, T., Christ, O., Cui, L., Finchilescu, G., González, R., Goto, N., Hornsey, M., Sharma, S., Susianto, H., and Zhang, A., 2014a. What makes a group worth dying for? Identity fusion fosters perception of familial ties, promoting self-sacrifice. Journal of Personality and Social Psychology, 106(6), 912.

Swann Jr., W. B., Gómez, Á., Buhrmester, M. D., López-Rodríguez, L., Jiménez, J., and Vázquez, A., 2014b. Contemplating the ultimate sacrifice: Identity fusion channels pro-group affect, cognition, and moral decision making. Journal of Personality and Social Psychology, 106(5), 713-727.

Tajfel, H. and Turner, J. C., 1979. An integrative theory of intergroup conflict. In W. G. Austin and S. Worchel (eds.), The Social Psychology of Intergroup Relations. Monterey: Brooks Cole, 33-47.

Whitehouse, H. and McQuinn, B. and Buhrmester, M. and Swann, W. B., 2014. Brothers in arms: Libyan revolutionaries bond like family. Proceedings of the National Academy of Sciences, 111(50), 17783-17785.

Whitehouse, H., Jong, J., Buhrmester, M. D., Gómez, Á., Bastian,
B., Kavanagh, C. M., Newson, M., Matthews, M., Lanman, J. A., McKay, R. and Gavrilets, S. The evolution of extreme cooperation via shared dysphoric experiences. Scientific Reports, 7, 44292.

Whitehouse, H., 2018. Dying for the group: Towards a general theory of extreme self-sacrifice. Behavioral and Brain Sciences.

Willard, A. K., 2018. Religion and prosocial behavior among the Indo-Fijians. Religion, Brain and Behavior, 8(2), 227-242.

Xygalatas, D., Kotherová, S., Maňo, P., Kundt, R., Cigán, J., Klocová, E. K., Lang, M., 2018. Big Gods in small places: the Random Allocation Game in Mauritius. Religion, Brain and Behavior, 8(2), 243-261. 


\section{Model 1}

Intercept

Ingroup Fusion

Outgroup Relations

Coastal Tannese

Hadza

Inland Tannese

Indo-Fijians

Marajó Brazilians

Mauritians

Tyvans

Yasawan-Fijians

Coastal Tannese (g)

Hadza (g)

Inland Tannese (g)

Indo-Fijians (g)

Marajó Brazilians (g)

Mauritians (g)

Tyvans (g)

Yasawa-Fijians (g)

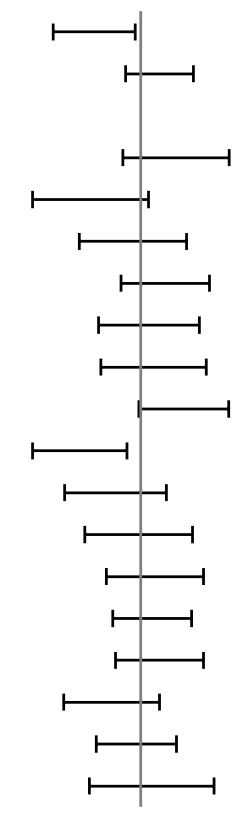

$-0.80$ $\begin{array}{lll}-0.30 & 0.20 & 0.70\end{array}$
Model 2

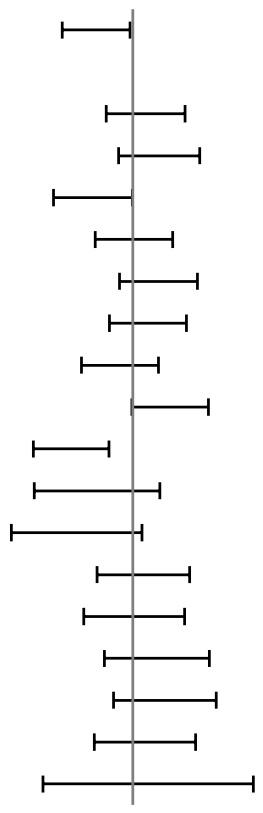

Intercept

Ingroup Fusion

Outgroup Relations

Coastal Tannese

Hadza

Inland Tannese

Indo-Fijians

Marajó Brazilians

Mauritians

Tyvans

Yasawan-Fijians

Coastal Tannese (o)

Hadza (o)

Inland Tannese (o)

Indo-Fijians (o)

Marajó Brazilians (o)

Mauritians (o)

Tyvans (o)

Yasawa-Fijians (o)

\section{Model 3}
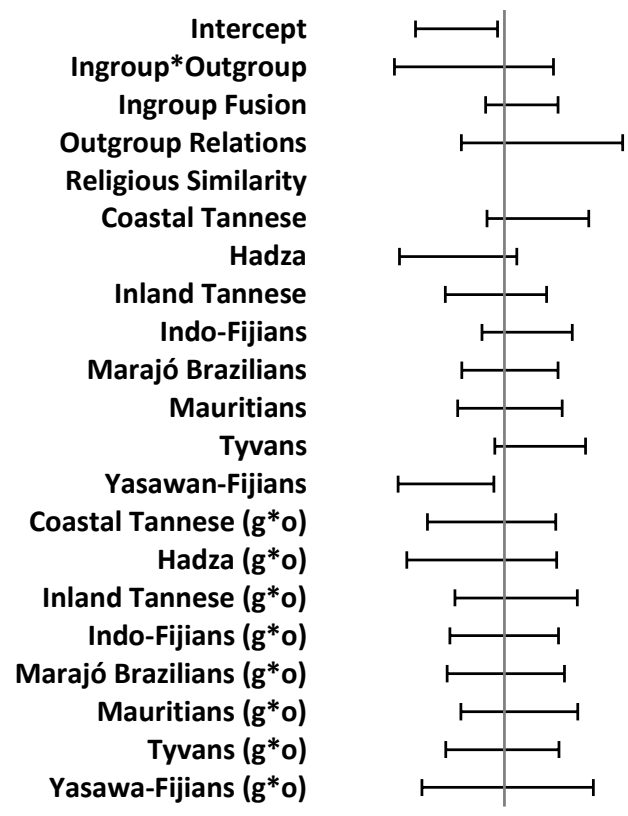

$-0.80$ $\begin{array}{lll}-0.30 & 0.20 & 0.70\end{array}$
$-0.80$

0.20

0.70

\section{Model 4}

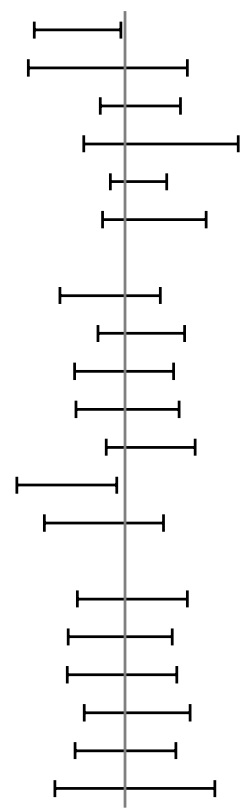

Intercept
Ingroup*Outgroup
Ingroup Fusion
Outgroup Relations
Religious Similarity
Coastal Tannese
Hadza
Inland Tannese
Indo-Fijians
Marajó Brazilians
Mauritians
Tyvans
Yasawan-Fijians
Coastal Tannese (g*o)
Hadza (g*o)
Inland Tannese (g*o)
Indo-Fijians (g*o)
Marajó Brazilians (g*o)
Mauritians (g*o)
Tyvans (g*o)
Yasawa-Fijians (g*o)

Figure 2. Model estimates of coin allocation and $95 \%$ credibility intervals. Gray line is at 0.0 , the threshold of no effect. Estimates $>0.0$ indicate sacrificing coins through fairer play, while estimates $<0.0$ indicate self-interested bias. Site names are intercepts with varied effects for ingroup $(\mathrm{g})$ and outgroup relations $(\mathrm{o})$ as well as their interaction $(\mathrm{g} * \mathrm{o})$. Model numbers correspond to definitions. 


\title{
Identity Fusion, Outgroups, and Sacrifice: A Cross- Cultural Test Supplementary Materials
}

\author{
Benjamin Grant Purzycki* and Martin Lang ${ }^{\text {b,c }}$ \\ aMax Planck Institute for Evolutionary Anthropology, Germany

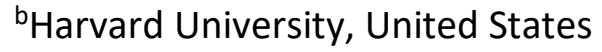 \\ 'Masaryk University, Czech Republic \\ *contact author email: benjamin_purzycki@eva.mpg.de
}

\section{Contents}

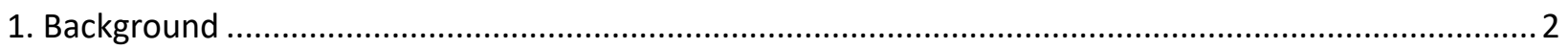

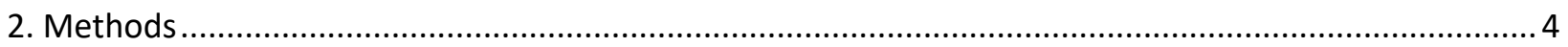

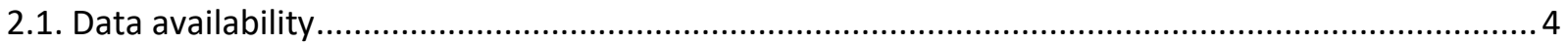

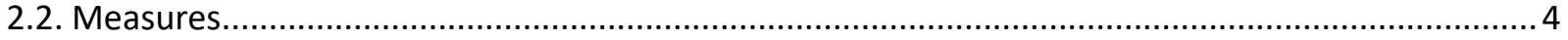

2.2.1. The Random Allocation Game and sacrifice ...................................................................... 4

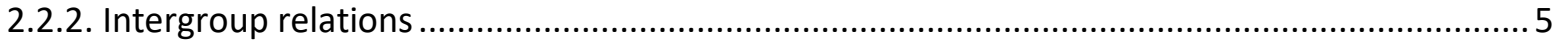

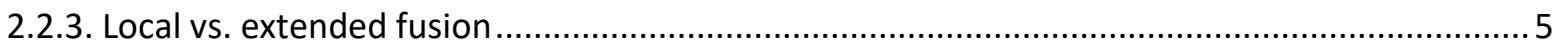

2.3. Data notes

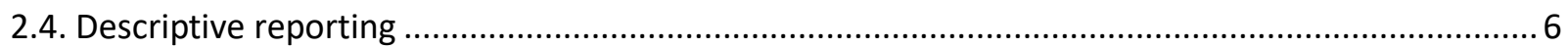

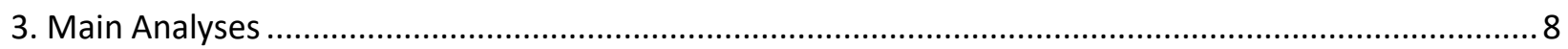

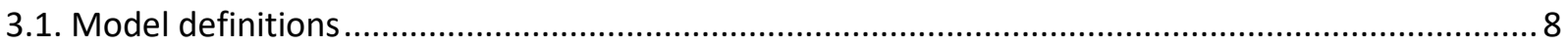

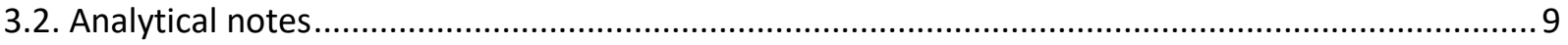

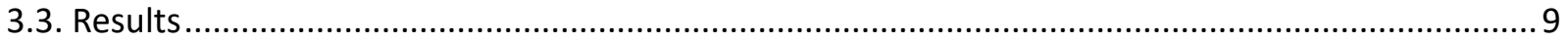

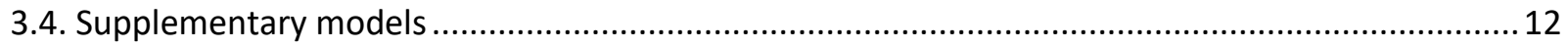

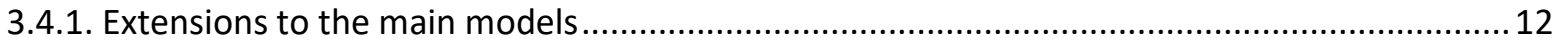

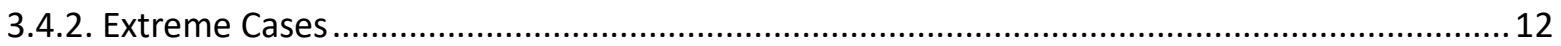

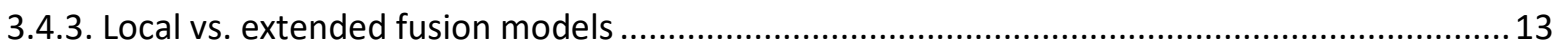

3.4.4. The Individualist Game in the Tyva Republic ..................................................................... 16

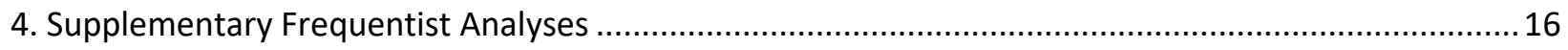

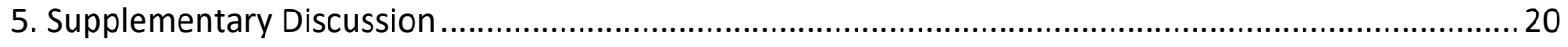

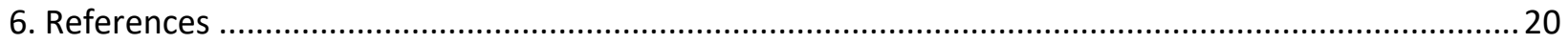




\section{Background}

Over the past decade, researchers have devoted increased attention to the theory of identity fusion, which proposes that the psychological state of identity fusion with a group mediates individuals' costly sacrifices on behalf of those groups (Swann, Jetten, Gómez, Whitehouse, \& Bastian, 2012). Based on the theory of self-verification (Swann, 1983; Swann \& Hill, 1982), identity fusion with a group has been shown to predict an array of self-reported pro-group behaviors. For example, Swann et al. (Swann, Gómez, Seyle, Morales, \& Huici, 2009) have shown that participants who select completely overlapping circles to represent their and their country's identities (fused individuals) expressed higher willingness to fight and die for their country. Interestingly, while the activation of personal identities had no effect on non-fused individuals, it increased the willingness to fight and die for the fused individuals to the same extent as activating social identities. The authors interpreted these results as a support for a functional equivalency of personal and social identities in fused individuals (Swann et al., 2009). In a subsequent study, Swann et al. (Swann, Gómez, Dovidio, Hart, \& Jetten, 2010) showed that the pictorial indicator of fusion predicted individual Spaniards' willingness to sacrifice their lives to save five other Spaniards. This effect extended even to five other Europeans, but not to Americans. Moreover, increasing agency through various manipulation of arousal further increased pro-group behavior of fused individuals (Swann, Gómez, Huici, Morales, \& Hixon, 2010).

Improving upon the pictorial measure that artificially divided participants into a binary category of fused/non-fused, Gómez at al. (2011) created a seven-item verbal measure of identity fusion showing that this continuous measure predicts participants' self-reported willingness to fight and die for their country and self-reported willingness to sacrifice one's life to save five other countrymen. Importantly, the relationship between the verbal measure of identity fusion and willingness to self-sacrifice was not mediated by decreased desire for selfpreservation in fused participants, but rather by increased devotion to the group (Swann, Gómez, et al., 2014). The same authors have also shown that under time pressure, the psychological state of identity fusion exerts even stronger effects over individuals' decisions to self-sacrifice for the group (Swann, Gómez, et al., 2014).

Further testing of the effects of identity fusion with samples of university students across 11 countries revealed robust relationships between identity fusion with one's country and willingness to fight and die for his or her country (Swann, Buhrmester, et al., 2014). This relationship holds also during armed conflicts and warfare. Whitehouse et al. (2014) surveyed revolutionaries during the 2011 conflict in Libya and found that fusion with one's battalion predicted willingness to engage in extreme behaviors on behalf of the battalion. This effect was even stronger for revolutionaries who were more fused with their battalion than with their families, suggesting that identity fusion may capitalize on fictive-kinship psychology. Indeed, 
increasing the salience of genetic relatedness or psychological similarity to other countrymen multiplied the effects of identity fusion on extreme pro-group behavior (Swann, Buhrmester, et al., 2014), a finding that was further supported by Vazquez et al. (Vázquez, Gómez, Ordoñana, Swann, \& Whitehouse, 2017) who showed that monozygotic twins are more fused and were more willing to make sacrifices for the other twin than dizygotic twins.

Summarizing these empirical findings, Whitehouse (2018) recently proposed a theoretical model that aims to delineate the causal chain of events that leads to identity fusion with a group and, in turn, leads to self-sacrifice for that group. At the beginning of this model are dysphoric experiences shared with other members of the group (e.g., extreme initiation rites or war-related distress), which trigger exegetical reflection on the meaning of shared suffering and transform personal identity such that people perceive the dysphoric experiences as the essence of shared group membership (Jong, Whitehouse, Kavanagh, \& Lane, 2015; Whitehouse et al., 2017). The experiential component of group membership causes identity fusion with the group, and fusion translates into psychological kinship with group members, which--interacting with an outgroup threat--may lead to self-sacrifice. In other words, fused people act as if other members of their group would be their genetic relatives--willing to sacrifice one's life, especially in the context of inter-group warfare.

Here, we assess the last part of Whitehouse's model, focusing on the role of outgroup relationships in moderating the effects of fusion with one's group on sacrificial behavior. We capitalize on the intuitive appeal of the pictorial fusion measure (Fig. S1) that allowed us to deploy fusion measurements across a host of small-scale societies, ranging from huntergathers, over pastoralists, to market-integrated (see Table 1). As the verbal fusion measure would be problematic at sites that do not use numeric representations (hence, answering on a scale is counterintuitive), the pictorial measure allowed us to assess fusion with ingroup and outgroup across all eight societies.

However, instead of testing willingness to fight and die for one's ingroup as is common in the identity fusion literature, we operationalized self-sacrificial behavior in economic terms as coins that one is willing to give up for other members of their ethnic and religious group. That is, we employed the Random Allocation Game (RAG henceforth; Hruschka et al., 2014; Purzycki et al., 2016b) where participants allocated 30 coins between themselves and anonymous members of their religious group residing in a geographically distant place (i.e., unlikely to ever reciprocate or retaliate). Utilizing natural dynamics between selfish and progroup behavior, this conceptualization of self-sacrifice as coins one sacrificed to the religious ingroup allowed us to measure continuous sacrificial behavior that should scale on the continuous pictorial measure of identity fusion. This avoids the assumption that self-sacrifice is a trait-like characteristic that needs a special, trait-like explanation (as assumed in Whitehouse's model). Since the endowment presented a strong incentive for participants (30 
coins were roughly equivalent to half a day's wage of the local average income, except for the Hadza, who used tokens each worth $8 \mathrm{oz}$. of maize), we were able to overcome problems and biases inherent in self-reports (e.g., see Lang, Bahna, Shaver, Reddish, \& Xygalatas, 2017) and measure actual self-sacrificial behavior.

Furthermore, rather than treating outgroup threat as a group-level exogenous variable imposed on participants, we measured individual-level relationships to religious outgroup using the same pictorial measure as for assessing ingroup fusion, making these measures directly comparable (see Tables 1 and SX for raw fusion means across our sites and Fig. S2 for density plots). This is not to say that the group-level variation in outgroup threat is unimportant, quite the contrary; but rather than imposing an outgroup threat artificially at each site or specifically targeting samples afflicted with intergroup aggression, we let it emerge from individual-level measures by employing varying effects of outgroup relations across our sites. The same is true for our ingroup fusion measure, allowing us to assess whether the hypothesized Ingroup Fusion*Outgroup interaction will emerge at the individual level after accounting for site-specific variance of this relationship (see section S3.1). That is, we assessed whether increasing ingroup fusion together with decreasing outgroup relations will predict higher rates of coin sacrifice that benefits religious and co-ethnic ingroups.

\section{Methods}

\subsection{Data availability}

The data we use are from the publicly available Evolution of Religion and Morality data set (Purzycki et al., 2016a). This article, the data set, all protocol materials, site descriptions, and sampling procedures are available here: https://github.com/bgpurzycki/Evolution-of-Religionand-Morality. The workflow for this specific project is and will be maintained at https://github.com/bgpurzycki/fusion. For results using this dataset for other purposes with other controls, see (Purzycki et al., 2016b, 2018).

\subsection{Measures}

\subsubsection{The Random Allocation Game and sacrifice}

Our behavioral measure was the Random Allocation Game, which detects systematic dishonest favoritism (Hruschka et al., 2014; Jiang, 2013). As described in the main text, participants have the opportunity to put more coins into their own cups than chance would allow. Coins should follow a binomial distribution, but participants tend to systematically favor themselves. As such, foregoing this opportunity is a sacrifice of real gains. Moreover, the recipients are distant ingroup members; co-ethnic, co-religious individuals who share the same beliefs and backgrounds as participants, but they are not likely to directly reciprocate or retaliate. Rather than make sacrifices for ingroup members who may reciprocate at a later time, the sacrifices we measure are completely lost opportunities of gaining wealth. Participants played two games: the Self Game (focused on here) and the Local Ingroup Game, where participants 
allocated coins between another anonymous distant ingroup member and an anonymous local ingroup member.

\subsubsection{Intergroup relations}

To measure fusion, we used the visual scale from Swann Jr. et al. (2009; figure S1 is actual visualization we used with updated targets for "Other") ported to numeric values of 1 to 5 . The questions we asked with this scale were as follows (variable names in data set in parentheses):

- Using these pictures, how emotionally close do you feel to defined geographically distant co-ethnic, co-religionist group?

[a specifically

- Using these pictures, how emotionally close do you feel toward members of [local co-religious, co-ethnic] group?

- Using these pictures, how emotionally close do you feel toward [specifically defined non-local religious and ethnic outgroup members]?

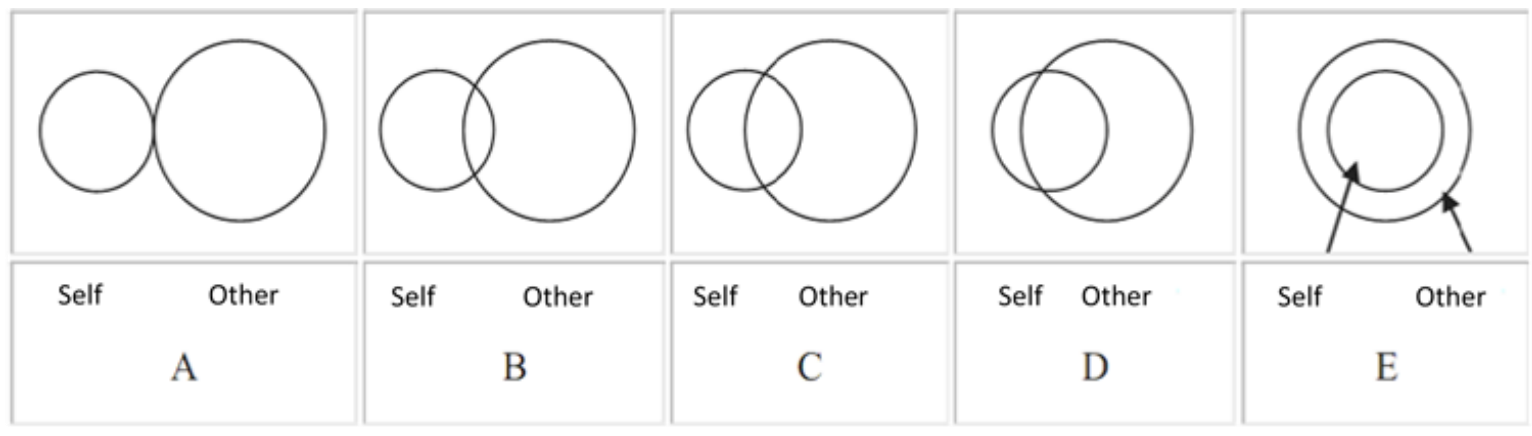

Figure S1 | Visual fusion scale adapted from Swann, et al. (2009) modified from Schubert and Otten (2002). Participants pointed to that which best represents their attitudes towards various others.

We also asked a question about participants' ratings of religious similarity to distant recipients (scale from -2 to 2 ):

- How similar are DISTANT's traditions/religious beliefs and practices with the LOCAL? (CORELSIM)

We do note that we are unsure as to whether or not overlapping circles function adequately as a metaphor for social relations across all contexts. In other words, the fusion measure might be too heavily reliant on a non-universal spatial metaphor. As illustrated below, we nevertheless found that by and large, individuals had far lower scores for ingroup fusion than its outgroup counterpart.

\subsubsection{Local vs. extended fusion}

The theory of identity fusion sketched above predicts that identity fusion is effective in facilitating pro-group behavior in interactions with both the local and extended ingroups (Swann, Buhrmester, et al., 2014; Swann, Gómez, Dovidio, et al., 2010). While participants are fused mainly with their ingroup (e.g. other Spaniards in the case of Swann et al. studies), they 
are often willing to sacrifice themselves even for members of groups with whom they share superordinate group membership (Europeans). That is, the pro-kin bias apparent in interaction with local ingroups (Hamilton, 1964) is projected onto members of the extended ingroup, especially if they share common cultural or morphological characteristics (Swann, Buhrmester, et al., 2014). This notion has been further elaborated in Whitehouse's model (Whitehouse, 2018), which posits that participants must first experience local fusion evoked by shared dysphoric experiences (within their community) that can be later projected onto extended ingroups.

In our current setup of the RAG, the money recipients from distant communities are extended ingroups, insofar as they are co-ethnic and co-religionist. We purposely selected distant ingroups due to having non-reciprocal relations participants because allocating to them lends itself to sacrifice inasmuch as the costs will never be directly reciprocated by those benefitting from them and it controls for any outgroup confounds. On the contrary, sacrificing resources to one's ingroup members typically involves returns through nonkin (Trivers, 1971) and kin alike (Hamilton, 1964). By way of analogy, engaging in warfare can benefit a multitude of anonymous others-who aren't fighting-from an external threat with no direct opportunity to reciprocate. Making a sacrifice of resources to one's community however, can have direct benefits, thus giving the allocations an investment-like quality instead of sacrifice.

Furthermore, we focused on ingroup fusion here primarily for the fact that the theory explicitly predicts that local fusion will predict sacrifice and represents the crucial basis of extended fusion. We nevertheless assessed the role of distant fusion on allocations by running the same main model and the model with only a simple and varying effect of local ingroup fusion (m1a and $\mathrm{mg}$ above) but replacing local ingroup fusion with distant ingroup fusion. Table S3 presents those results (section 3.4.2).

\subsection{Data notes}

While we have data for the Hadza's fusion scores (as it was a visual scale to which participants pointed), we do not have data for their perceived religious similarity due to difficulty with numerical scales. As indicated by Figure S2, the distributions of their fusion scores were intuitive insofar as they felt emotionally closer to other Hadza than to Datoga herders. In the original data file, their scale was from 0 to 4 , which was recoded to 1 to 5 to be consistent with the rest of the data. One individual in the Tyvan sample responded at the halfway point between 4 and 5 on the ingroup fusion scale. This was recoded as 5.

\subsection{Descriptive reporting}

Figure S2 is a density plot showing the cross-site distribution of ingroup and outgroup relation scores. Across sites, it is clear that people are rating their emotional proximity to ingroups more than their outgroups. In other words, participants were systematically more fused with their ingroups than outgroups (see main text for statistics). 

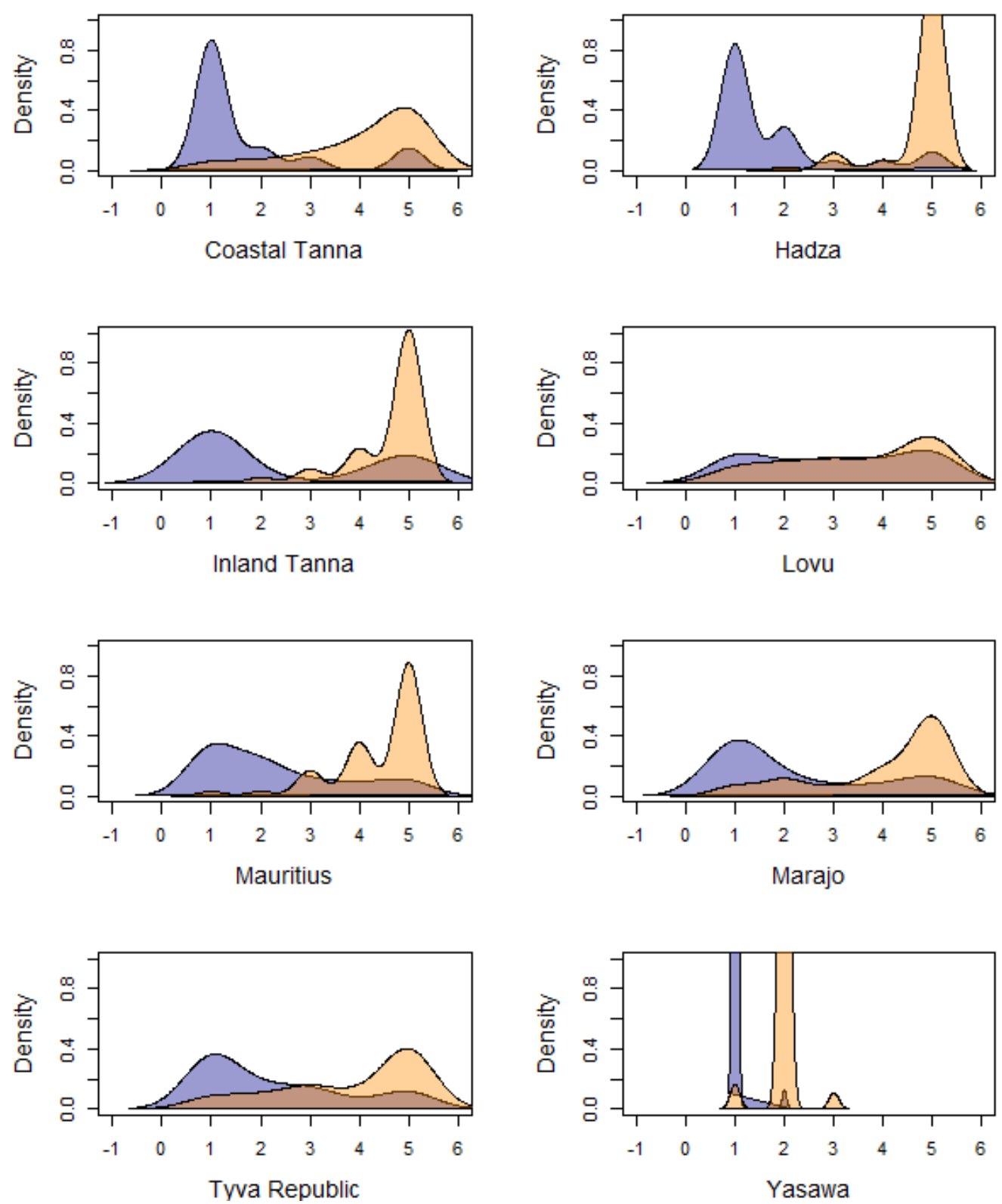

Figure S2 | Density plots of ingroup (orange) and outgroup (blue) fusion across eight field sites. Recoded scales were from 1 to 5 .

Table S1 is a table of counts for participant Ingroup*Outgroup scores. The modal response in the matrix is high ingroup fusion (5) and low outgroup relations (1), totaling 146 ( $26 \%$ of the sample). Figure S3 includes 2D surface plot of the raw allocation data across values for ingroup and outgroup ratings. Note that the data were interpolated in order to show continuous transitions between the outgroup and ingroup categories. Note too, that the peaks are misleading insofar as the plot surfaces are means. The two peaks represent a total of three participants (e.g., one individual with low ingroup fusion and high outgroup scores put 20 coins in the cup opposite to him or herself); see Table S1. 
Table S1 | Participant responses to fusion questions of ingroups and outgroups. Left panel reports counts of participants and right panel reports means. 1 = lowest possible score (separate), $5=$ maximum (fused). Bold values indicate the values of the two peaks in the plots.

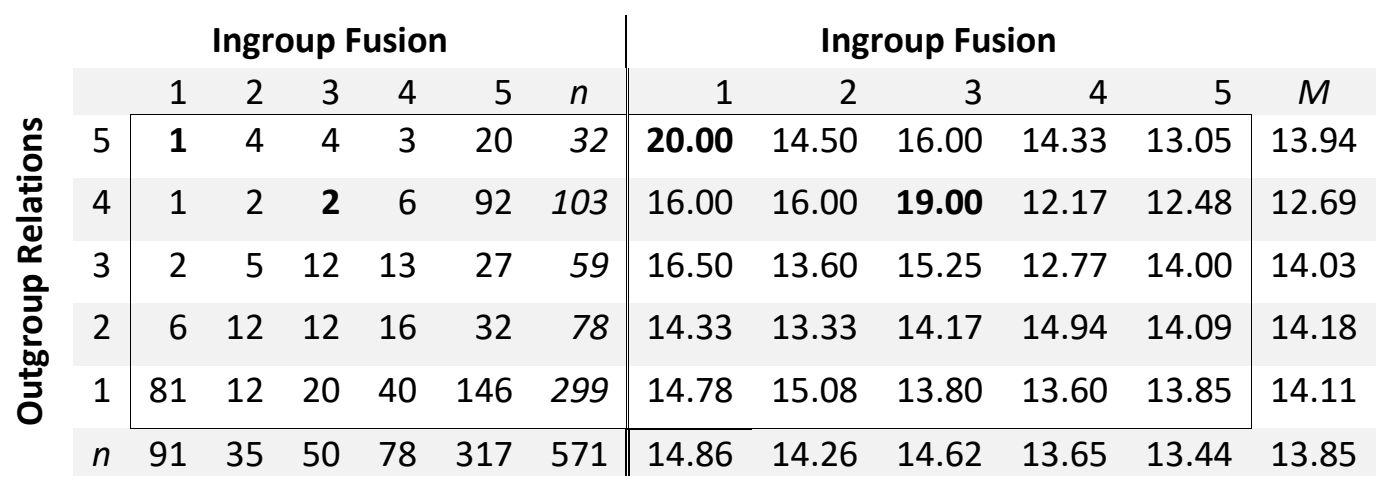

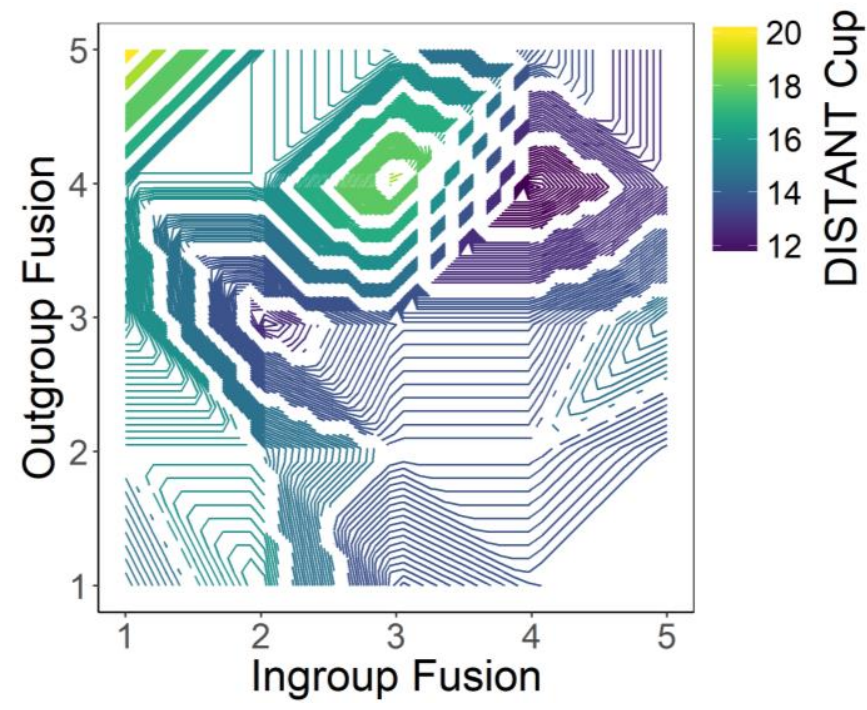

Figure S3 | 2D surface plot of raw data showing the interaction between ingroup fusion and outgroup relations in predicting DISTANT allocations. See Table S1 for data.

\section{Main Analyses}

\subsection{Model definitions}

Recall that the linear component of our main model was defined as follows:

$$
\operatorname{logit}\left(p_{i}\right)=\alpha_{S(i)}+b_{S(i)}{ }^{*} g_{i}+\gamma_{S(i)}{ }^{*} o_{i}+\psi_{S(i)}{ }^{*} g_{i} * o_{i}
$$

where $g$ is the ingroup fusion value and $o$ is the outgroup counterpart. We modelled their effects simply for individuals, denoted by subscript $i$, but also varying across groups, as denoted by the subscript $s$. The three other model specifications were as follows:

$$
\begin{array}{ll}
\operatorname{logit}\left(p_{i}\right)=\alpha_{S(i)}+\lambda_{s} * r_{i}+b_{S(i)} * g_{i}+\gamma_{S(i)} * o_{i}+\psi_{S(i)} * g_{i} * o_{i}(\mathrm{~m} 1 \mathrm{~b}) & \\
\operatorname{logit}\left(p_{i}\right)=\alpha_{S(i)}+b_{S(i)} * g_{i} & (\mathrm{mg}) \\
\operatorname{logit}\left(p_{i}\right)=\alpha_{S(i)}+\gamma_{S(i)}{ }^{*} o_{i} & (\mathrm{mo})
\end{array}
$$


Equation $\mathrm{m} 1 \mathrm{~b}$ is the same as equation $\mathrm{m} 1 \mathrm{a}$, but adds the variable $r$, which represents reported religious similarity of distant players. Equations $\mathrm{mg}$ and mo are the simplest models, where ingroup and outgroup relations are treated as simple effects and effects varying across sites, respectively. The prior distribution definitions remain the same. We use the LKJCorr prior (where $\eta=4$ ) to conservatively address extreme correlations (Lewandowski, Kurowicka, \& Joe, 2009; see McElreath, 2018, pp. 393-394).

\subsection{Analytical notes}

The analytical strategy we adopt here primarily focuses on the theories defined in the fusion literature. That is, we stick closely to the theory that has been developed by modelling it to the best of our ability, and not including other factors (e.g., conventional demographic "controls") that may affect the game outcomes or absorb the effects. Specifically, Whitehouse (2018) predicts that perceived sharedness leads to local fusion which in turn leads to psychological kinship. Finally, outgroup threat moderates the relationship between psychological kinship and self-sacrifice. While we were not able to directly assess the perceived psychological kinship, we measured local fusion, hence we should observe the same effects as if we would use perceived psychological kinship (given it is a mediator).

To model monotonic effects, we used the brms package (Bürkner, 2017; Version 2.1.0) for use in R (R Core Team, 2016). We attempted to model both outgroup and ingroup fusion as independent varying effects across groups, but models would not run, likely due to their inverse correlation and distributions (see Figure S2 above). All plots other than the density plots were created using the package ggplot2 (Wickham, 2009). Note that specific values in the Bayesian models may change slightly across software as the brms package and rstan set seeds differently. We set global and per-model seeds at 7 .

\subsection{Results}

Table S2 reports the results from the main regression models. The $\mathrm{g}_{i}{ }^{*} \mathrm{o}_{i}$ interaction is easiest to view in Figure S4, where the highest concentration of sacrificed coins-in yellow-is when outgroup relation scores are high (cf. Figure S2). Holding the effect of religious similarity constant (and removing the Hadza) shifts the concentration of sacrifice toward the higher end of the ingroup fusion scale. Figure $\mathrm{S} 5$ then displays the same results from model $\mathrm{m} 1 \mathrm{a}$ across three levels of outgroup scores (min, middle, max) with $95 \%$ credibility intervals. The relatively wide credibility intervals for maximal levels of outgroup relations indicate that the predicted high allocations in this group (cf. Figure S4) were quite variable. Overall, however, these figures indicate that there was no difference in ingroup sacrifice across the outgroup relations measure. 

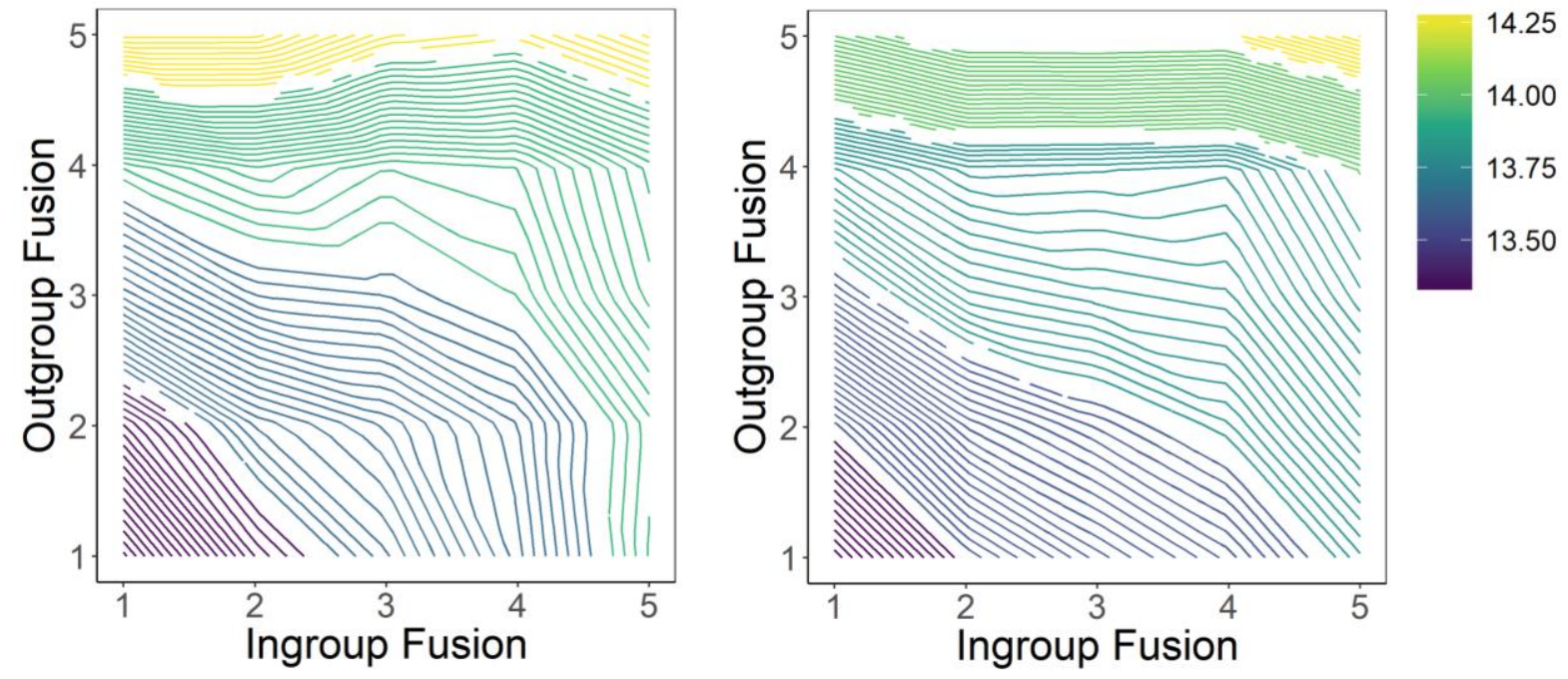

Figure S4 | Surface plot of individual-level interaction between ingroup and outgroup scores on allocation to distant ingroup cup. X-axis is ingroup (g) and $\mathrm{y}$-axis is outgroup (o) scores. Left plot is model m1a and right plot is m1b.

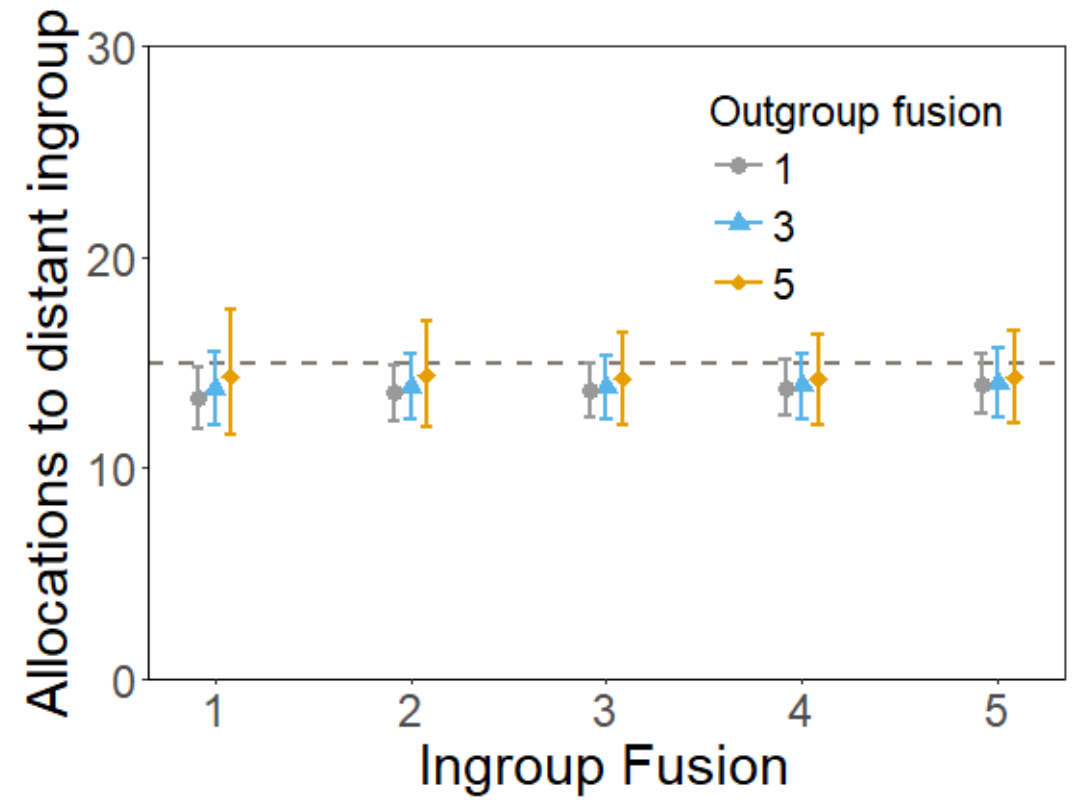

Figure S5 | Estimated means with 95\% credibility intervals of allocations to distant ingroups across three levels of outgroup relations scores. Estimates from model m1a. The dashed line indicates impartial allocations (half of endowment) to religious ingroups. 
Table S2 | Estimates and 95\% credibility intervals of models reported in main text (Figure 1). Varying effects for ingroup fusion are denoted with (g) and outgroup with an (o).

\begin{tabular}{|c|c|c|c|c|c|c|c|}
\hline & $\begin{array}{c}\beta \\
{[95 \% \mathrm{Cl}]}\end{array}$ & $\begin{array}{c}\beta \\
{[95 \% \mathrm{Cl}]}\end{array}$ & $\begin{array}{c}\beta \\
{[95 \% \mathrm{Cl}]}\end{array}$ & $\begin{array}{c}\beta \\
{[95 \% \mathrm{Cl}]}\end{array}$ & $\begin{array}{c}\beta \\
{[95 \% \mathrm{Cl}]}\end{array}$ & $\begin{array}{c}\beta \\
{[95 \% \mathrm{Cl}]}\end{array}$ & $\begin{array}{c}\beta \\
{[95 \% \mathrm{Cl}]}\end{array}$ \\
\hline Intercept & $\begin{array}{c}-0.22 \\
{[-0.42,-0.03]}\end{array}$ & $\begin{array}{c}-0.23 \\
{[-0.44,-0.02]}\end{array}$ & $\begin{array}{c}-0.22 \\
{[-0.42,-0.03]}\end{array}$ & $\begin{array}{c}-0.17 \\
{[-0.33,-0.01]}\end{array}$ & $\begin{array}{c}-0.23 \\
{[-0.42,-0.05]}\end{array}$ & $\begin{array}{c}-0.22 \\
{[-0.43,-0.02]}\end{array}$ & $\begin{array}{c}-0.23 \\
{[-0.43,-0.03]}\end{array}$ \\
\hline Ing.*Outg. & $\begin{array}{c}-0.10 \\
{[-0.52,0.23]}\end{array}$ & $\begin{array}{c}-0.05 \\
{[-0.47,0.30]}\end{array}$ & -- & -- & $\begin{array}{c}-0.09 \\
{[-0.45,0.19]}\end{array}$ & $\begin{array}{c}-0.11 \\
{[-0.54,0.23]}\end{array}$ & $\begin{array}{c}-0.10 \\
{[-0.51,0.24]}\end{array}$ \\
\hline Rel. Similarity & -- & $\begin{array}{c}0.07 \\
{[-0.07,0.20]}\end{array}$ & -- & -- & -- & -- & -- \\
\hline Ingroup Fusion & $\begin{array}{c}0.08 \\
{[-0.09,0.25]}\end{array}$ & $\begin{array}{c}0.07 \\
{[-0.12,0.27]}\end{array}$ & $\begin{array}{c}0.09 \\
{[-0.07,0.25]}\end{array}$ & -- & $\begin{array}{c}0.08 \\
{[-0.04,0.23]}\end{array}$ & $\begin{array}{c}0.08 \\
{[-0.09,0.27]}\end{array}$ & $\begin{array}{c}0.08 \\
{[-0.09,0.26]}\end{array}$ \\
\hline $\begin{array}{l}\text { Outgroup } \\
\text { Relations }\end{array}$ & $\begin{array}{c}0.14 \\
{[-0.20,0.56]}\end{array}$ & $\begin{array}{c}0.14 \\
{[-0.20,0.54]}\end{array}$ & -- & $\begin{array}{c}0.07 \\
{[-0.12,0.24]}\end{array}$ & $\begin{array}{c}0.14 \\
{[-0.19,0.52]}\end{array}$ & $\begin{array}{c}0.15 \\
{[-0.20,0.59]}\end{array}$ & $\begin{array}{c}0.14 \\
{[-0.21,0.54]}\end{array}$ \\
\hline Treatment & -- & -- & -- & -- & -- & $\begin{array}{c}-0.02 \\
{[-0.09,0.06]}\end{array}$ & -- \\
\hline Game Order & -- & -- & -- & -- & -- & -- & $\begin{array}{c}0.00 \\
{[-0.06,0.07]}\end{array}$ \\
\hline Coastal Tannese & $\begin{array}{c}0.14 \\
{[-0.08,0.40]}\end{array}$ & $\begin{array}{c}0.11 \\
{[-0.11,0.39]}\end{array}$ & $\begin{array}{c}0.13 \\
{[-0.09,0.43]}\end{array}$ & $\begin{array}{c}0.12 \\
{[-0.06,0.31]}\end{array}$ & $\begin{array}{c}0.12 \\
{[-0.07,0.31]}\end{array}$ & $\begin{array}{c}0.14 \\
{[-0.08,0.42]}\end{array}$ & $\begin{array}{c}0.14 \\
{[-0.08,0.42]}\end{array}$ \\
\hline Hadza & $\begin{array}{c}-0.19 \\
{[-0.50,0.06]}\end{array}$ & -- & $\begin{array}{c}-0.22 \\
{[-0.52,0.04]}\end{array}$ & $\begin{array}{c}-0.18 \\
{[-0.37,-0.00]}\end{array}$ & $\begin{array}{c}-0.19 \\
{[-0.38,-0.01]}\end{array}$ & $\begin{array}{c}-0.19 \\
{[-0.50,0.07]}\end{array}$ & $\begin{array}{c}-0.18 \\
{[-0.49,0.08]}\end{array}$ \\
\hline Inland Tannese & $\begin{array}{c}-0.03 \\
{[-0.28,0.20]}\end{array}$ & $\begin{array}{c}-0.06 \\
{[-0.31,0.17]}\end{array}$ & $\begin{array}{c}-0.02 \\
{[-0.29,0.22]}\end{array}$ & $\begin{array}{c}0.01 \\
{[-0.17,0.18]}\end{array}$ & $\begin{array}{c}-0.00 \\
{[-0.18,0.18]}\end{array}$ & $\begin{array}{c}-0.03 \\
{[-0.30,0.22]}\end{array}$ & $\begin{array}{c}-0.02 \\
{[-0.28,0.21]}\end{array}$ \\
\hline Indo-Fijians & $\begin{array}{c}0.11 \\
{[-0.11,0.32]}\end{array}$ & $\begin{array}{c}0.08 \\
{[-0.13,0.29]}\end{array}$ & $\begin{array}{c}0.12 \\
{[-0.09,0.33]}\end{array}$ & $\begin{array}{c}0.12 \\
{[-0.06,0.30]}\end{array}$ & $\begin{array}{c}0.13 \\
{[-0.05,0.32]}\end{array}$ & $\begin{array}{c}0.11 \\
{[-0.12,0.33]}\end{array}$ & $\begin{array}{c}0.11 \\
{[-0.11,0.33]}\end{array}$ \\
\hline Marajó Brazilians & $\begin{array}{c}0.04 \\
{[-0.20,0.25]}\end{array}$ & $\begin{array}{c}0.02 \\
{[-0.24,0.23]}\end{array}$ & $\begin{array}{c}0.06 \\
{[-0.20,0.28]}\end{array}$ & $\begin{array}{c}0.07 \\
{[-0.11,0.25]}\end{array}$ & $\begin{array}{c}0.07 \\
{[-0.11,0.26]}\end{array}$ & $\begin{array}{c}0.04 \\
{[-0.22,0.26]}\end{array}$ & $\begin{array}{c}0.04 \\
{[-0.20,0.25]}\end{array}$ \\
\hline Mauritians & $\begin{array}{c}-0.00 \\
{[-0.22,0.27]}\end{array}$ & $\begin{array}{c}-0.02 \\
{[-0.24,0.26]}\end{array}$ & $\begin{array}{c}0.03 \\
{[-0.19,0.32]}\end{array}$ & $\begin{array}{c}-0.05 \\
{[-0.24,0.12]}\end{array}$ & $\begin{array}{c}-0.06 \\
{[-0.24,0.12]}\end{array}$ & $\begin{array}{c}0.01 \\
{[-0.23,0.30]}\end{array}$ & $\begin{array}{c}0.00 \\
{[-0.23,0.28]}\end{array}$ \\
\hline Tyvans & $\begin{array}{c}0.16 \\
{[-0.04,0.39]}\end{array}$ & $\begin{array}{c}0.11 \\
{[-0.09,0.34]}\end{array}$ & $\begin{array}{c}0.19 \\
{[-0.01,0.42]}\end{array}$ & $\begin{array}{c}0.17 \\
{[-0.00,0.35]}\end{array}$ & $\begin{array}{c}0.17 \\
{[-0.00,0.35]}\end{array}$ & $\begin{array}{c}0.17 \\
{[-0.05,0.39]}\end{array}$ & $\begin{array}{c}0.17 \\
{[-0.05,0.39]}\end{array}$ \\
\hline Yasawan-Fijians & $\begin{array}{c}-0.26 \\
{[-0.50,-0.05]}\end{array}$ & $\begin{array}{c}-0.25 \\
{[-0.52,-0.04]}\end{array}$ & $\begin{array}{c}-0.27 \\
{[-0.52,-0.07]}\end{array}$ & $\begin{array}{c}-0.28 \\
{[-0.46,-0.11]}\end{array}$ & $\begin{array}{c}-0.24 \\
{[-0.43,-0.07]}\end{array}$ & $\begin{array}{c}-0.26 \\
{[-0.52,-0.05]}\end{array}$ & $\begin{array}{c}-0.25 \\
{[-0.51,-0.05]}\end{array}$ \\
\hline Coastal Tannese $^{v}$ & $\begin{array}{c}-0.03 \\
{[-0.37,0.24]}\end{array}$ & $\begin{array}{c}-0.05 \\
{[-0.39,0.19]}\end{array}$ & $\begin{array}{c}-0.05 \\
{[-0.36,0.12]}\end{array}$ & $\begin{array}{c}-0.11 \\
{[-0.45,0.12]}\end{array}$ & $\begin{array}{c}-0.10 \\
{[-0.44,0.12]}\end{array}$ & $\begin{array}{c}-0.04 \\
{[-0.38,0.24]}\end{array}$ & $\begin{array}{c}-0.04 \\
{[-0.40,0.25]}\end{array}$ \\
\hline Hadzav & $\begin{array}{c}-0.06 \\
{[-0.46,0.25]}\end{array}$ & -- & $\begin{array}{c}-0.01 \\
{[-0.27,0.25]}\end{array}$ & $\begin{array}{c}-0.18 \\
{[-0.56,0.04]}\end{array}$ & $\begin{array}{c}-0.16 \\
{[-0.53,0.05]}\end{array}$ & $\begin{array}{c}-0.07 \\
{[-0.48,0.25]}\end{array}$ & $\begin{array}{c}-0.06 \\
{[-0.46,0.27]}\end{array}$ \\
\hline Inland Tannese ${ }^{v}$ & $\begin{array}{c}0.03 \\
{[-0.23,0.35]}\end{array}$ & $\begin{array}{c}0.02 \\
{[-0.23,0.30]}\end{array}$ & $\begin{array}{c}0.04 \\
{[-0.16,0.30]}\end{array}$ & $\begin{array}{c}0.03 \\
{[-0.16,0.26]}\end{array}$ & $\begin{array}{c}0.04 \\
{[-0.17,0.28]}\end{array}$ & $\begin{array}{c}0.03 \\
{[-0.26,0.37]}\end{array}$ & $\begin{array}{c}0.02 \\
{[-0.26,0.34]}\end{array}$ \\
\hline Indo-Fijians $^{v}$ & $\begin{array}{c}0.00 \\
{[-0.26,0.26]}\end{array}$ & $\begin{array}{c}-0.01 \\
{[-0.27,0.23]}\end{array}$ & $\begin{array}{c}0.03 \\
{[-0.13,0.25]}\end{array}$ & $\begin{array}{c}0.01 \\
{[-0.22,0.24]}\end{array}$ & $\begin{array}{c}-0.00 \\
{[-0.23,0.22]}\end{array}$ & $\begin{array}{c}0.00 \\
{[-0.26,0.27]}\end{array}$ & $\begin{array}{c}0.00 \\
{[-0.25,0.26]}\end{array}$ \\
\hline Marajó Brazilians ${ }^{\vee}$ & $\begin{array}{c}0.01 \\
{[-0.27,0.29]}\end{array}$ & $\begin{array}{c}-0.00 \\
{[-0.28,0.25]}\end{array}$ & $\begin{array}{c}0.05 \\
{[-0.12,0.30]}\end{array}$ & $\begin{array}{c}0.08 \\
{[-0.13,0.35]}\end{array}$ & $\begin{array}{c}0.07 \\
{[-0.14,0.34]}\end{array}$ & $\begin{array}{c}0.01 \\
{[-0.26,0.30]}\end{array}$ & $\begin{array}{c}0.01 \\
{[-0.27,0.30]}\end{array}$ \\
\hline Mauritians $^{v}$ & $\begin{array}{c}0.04 \\
{[-0.20,0.35]}\end{array}$ & $\begin{array}{c}0.04 \\
{[-0.20,0.31]}\end{array}$ & $\begin{array}{c}-0.07 \\
{[-0.37,0.09]}\end{array}$ & $\begin{array}{c}0.10 \\
{[-0.09,0.38]}\end{array}$ & $\begin{array}{c}0.11 \\
{[-0.09,0.40]}\end{array}$ & $\begin{array}{c}0.05 \\
{[-0.22,0.37]}\end{array}$ & $\begin{array}{c}0.04 \\
{[-0.22,0.36]}\end{array}$ \\
\hline Tyvans ${ }^{v}$ & $\begin{array}{c}-0.00 \\
{[-0.28,0.26]}\end{array}$ & $\begin{array}{c}-0.00 \\
{[-0.24,0.24]}\end{array}$ & $\begin{array}{c}-0.01 \\
{[-0.21,0.17]}\end{array}$ & $\begin{array}{c}0.04 \\
{[-0.18,0.29]}\end{array}$ & $\begin{array}{c}0.04 \\
{[-0.19,0.30]}\end{array}$ & $\begin{array}{c}-0.00 \\
{[-0.29,0.26]}\end{array}$ & $\begin{array}{c}-0.01 \\
{[-0.29,0.25]}\end{array}$ \\
\hline Yasawa-Fijians $^{\vee}$ & $\begin{array}{c}0.01 \\
{[-0.39,0.42]}\end{array}$ & $\begin{array}{c}0.02 \\
{[-0.34,0.43]}\end{array}$ & $\begin{array}{c}0.02 \\
{[-0.24,0.35]} \\
\end{array}$ & $\begin{array}{c}0.03 \\
{[-0.41,0.56]}\end{array}$ & $\begin{array}{c}0.02 \\
{[-0.40,0.53]}\end{array}$ & $\begin{array}{c}0.01 \\
{[-0.40,0.44]}\end{array}$ & $\begin{array}{c}0.01 \\
{[-0.37,0.42]}\end{array}$ \\
\hline 'Varied effect & $g^{*} \mathrm{o}$ & $g^{*} \mathrm{o}$ & $\mathrm{g}$ & 0 & 0 & g*o & g*o \\
\hline Panel from Fig. 1 & a & $b$ & c & $d$ & -- & -- & -- \\
\hline Model (R script) & $\mathrm{m} 1 \mathrm{a}$ & $\mathrm{m} 1 \mathrm{~b}$ & $\mathrm{mg}$ & mo & $\mathrm{ms}$ & $\mathrm{mp}$ & $\mathrm{mt}$ \\
\hline
\end{tabular}




\subsection{Supplementary models}

\subsubsection{Extensions to the main models}

In addition to the four main models, we ran a few additional model specifications for robustness checking purposes. In all of these models, we maximize sample size by not including the religious similarity variable, which would force dropping the Hadza. The first model (model $\mathrm{ms}$ in Table S2) varies only outgroup relations scores across sites (instead of the Outgroup*Ingroup fusion interaction), thus leaving the interaction effect only at the level of individuals:

$$
\operatorname{logit}\left(p_{i}\right)=\alpha_{S(i)}+\gamma_{S(i)}{ }^{*} o_{i}+\psi_{i}{ }^{*} g_{i}{ }^{*} o_{i}
$$

We also added model specifications identical to the main model (m1a), but with either one of two experimental checks included. As all participants played at least two counterbalanced variations of the experimental game (one where the cups specified were for ingroups instead of for participants and the other cup was for another anonymous distant co-religionist, co-ethnic), we hold constant the game order (model mt in Table S2). Some participants (Lovu, Mauritius, Tyva Republic, and Yasawans) also played in a treatment condition with religious primes (model $\mathrm{mp}$ in Table S2). We hold this constant as well. Note that across model specifications, the main results are robust to such controls and the results are qualitatively the same across all specifications.

\subsubsection{Extreme Cases}

As mentioned in the main text, much of the work focuses on the extreme ends of the fusion scale and dichotomizes the values where any response less than the extreme is "unfused." For the sake of illustration, we include similar models as those defined above, but we dummy coded the fusion data; all ingroup fusion scores $<5$ were recoded as zeroes and all of those on the extreme end were recoded as 1 . Similarly, we recoded the outgroup relations data, but reversed the scale, so that all 1's were recoded as 1 (i.e., the extreme opposite of fused) and all values $>1$ were recoded as zero. Table S3 reports the frequencies of responses on the full data set (i.e., without missing values removed).

Note that for both ingroup and outgroup scales, Yasawans had floor effects. No individual considered themselves fused (i.e., $0 \%$ of the subsample answered the scale by pointing to the image representing fusion). Similarly, $99 \%$ of this subsample answered with the lowest possible value on this scale. Because of this, the dummy coded data did not provide sufficient within site variation to model. As such, the output of the regression analyses (Table S3) do not include Yasawans. This represents one methodological problem with post hoc dummy coding of such values in cross-cultural research.

As illustrated in Table S4, there were no substantive differences across dummy coded data and the main effects for ingroup fusion; ingroup fusion still shows a positive - but slightassociation with game allocations (cf. Tab. S1 and Tab. S3, model mg). Note that in model m1bin, the effect for Inland Tanna was quite strong; the overwhelming bulk of the effect's 
probability mass is on the positive side of zero $(95 \% \mathrm{Cl}=-0.04,0.27)$. Mauritius, on the other hand, showed the reverse effect $(95 \% \mathrm{Cl}=-0.25,0.04)$. However, it is worth pointing out that the coefficient sizes represent only a small increase/decrease of allocation probability around $1.7 \%$.

On average, the reverse-and-dummy coded outgroup relations variable (called "detachment" in the table) showed no association with allocations. However, the output for model $\mathrm{m} 2$ bin shows that it does have differential effects across sites. Outgroup detachment predicts sacrificing coins among the Coastal Tanna and Hadza samples while it predicts selffavoritism among Marajó Brazilians and Mauritians. Similar to the main interaction models in S2, on average, individuals who are fused with ingroup and detached from outgroups are less likely to sacrifice coins (though the effect is unreliable, $-0.05,95 \% \mathrm{Cl}=[-0.22,0.11]$ ). The sitelevel ingroup*outgroup interaction parallels the varying effects in the outgroup model (m2bin).

\subsubsection{Local vs. extended fusion models}

Recall in section 2.2.3 where we discussed the distinction between local fusion and extended fusion. Table S5 reports these details. The results are qualitatively similar to the results of the target models; the interaction shows no association with game outcome, but distant ingroup fusion is associated with greater sacrifice.

Table S3 | Frequencies and proportions of extreme values for ingroup (top) and outgroup (bottom) fusion. In the top panel, the proportions are those in the full data set who answered as "fused" (a value of 5). In the bottom panel, the proportions are those in the full data set who answered with a 1, the least fused.

\begin{tabular}{|c|c|c|c|c|c|c|c|c|}
\hline & Site & 1 & 2 & 3 & 4 & 5 & $\mathbf{n}$ & Prop. 5 \\
\hline \multirow{9}{*}{ 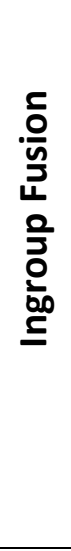 } & Coastal Tanna & 3 & 3 & 5 & 9 & 22 & 42 & 0.52 \\
\hline & Hadza & 1 & 1 & 5 & 3 & 58 & 68 & 0.85 \\
\hline & Inland Tanna & 1 & 2 & 5 & 12 & 53 & 73 & 0.73 \\
\hline & Lovu & 10 & 11 & 13 & 11 & 30 & 75 & 0.40 \\
\hline & Marajo & 7 & 8 & 4 & 12 & 38 & 69 & 0.55 \\
\hline & Mauritius & 2 & 2 & 11 & 23 & 57 & 95 & 0.60 \\
\hline & Tyva Republic & 10 & 8 & 14 & 8 & 41 & 81 & 0.51 \\
\hline & Yasawa & 3 & 68 & 2 & 0 & 0 & 73 & 0.00 \\
\hline & & 1 & 2 & 3 & 4 & 5 & $\mathbf{n}$ & Prop. 1 \\
\hline \multirow{8}{*}{ 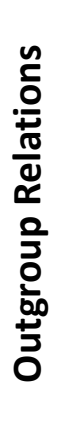 } & Coastal Tanna & 29 & 5 & 3 & 0 & 5 & 42 & 0.69 \\
\hline & Hadza & 41 & 14 & 3 & 3 & 6 & 67 & 0.61 \\
\hline & Inland Tanna & 45 & 1 & 1 & 3 & 23 & 73 & 0.62 \\
\hline & Lovu & 19 & 10 & 14 & 11 & 21 & 75 & 0.25 \\
\hline & Marajo & 36 & 9 & 5 & 5 & 12 & 67 & 0.54 \\
\hline & Mauritius & 38 & 25 & 11 & 9 & 12 & 95 & 0.40 \\
\hline & Tyva Republic & 37 & 13 & 13 & 4 & 12 & 79 & 0.47 \\
\hline & Yasawa & 72 & 1 & 0 & 0 & 0 & 73 & 0.99 \\
\hline
\end{tabular}


Table S4 | Extreme value models. Models use dummy coded values for ingroup fusion (where 5 on the scale was recoded as 1 , all others as 0 ) and outgroup detachment (where 1 's on the scale were recoded as 1 and all others $0)$.

\begin{tabular}{|c|c|c|c|}
\hline & $\begin{array}{c}\beta \\
{[95 \% \mathrm{Cl}]}\end{array}$ & $\begin{array}{c}\beta \\
{[95 \% \mathrm{Cl}]}\end{array}$ & $\begin{array}{c}\beta \\
{[95 \% \mathrm{Cl}]}\end{array}$ \\
\hline Intercept & $\begin{array}{c}-0.13 \\
{[-0.29,0.03]}\end{array}$ & $\begin{array}{c}-0.10 \\
{[-0.28,0.07]}\end{array}$ & $\begin{array}{c}-0.14 \\
{[-0.35,0.04]}\end{array}$ \\
\hline Ing. *Outg. & -- & -- & $\begin{array}{c}-0.05 \\
{[-0.22,0.11]}\end{array}$ \\
\hline $\begin{array}{r}\text { Ingroup Fused? } \\
(\text { yes = 1) }\end{array}$ & $\begin{array}{c}0.04 \\
{[-0.07,0.15]}\end{array}$ & -- & $\begin{array}{c}0.06 \\
{[-0.06,0.19]}\end{array}$ \\
\hline $\begin{array}{r}\text { Outgroup } \\
\text { detached? }(\text { yes = } 1)\end{array}$ & -- & $\begin{array}{c}-0.02 \\
{[-0.14,0.11]}\end{array}$ & $\begin{array}{c}0.01 \\
{[-0.12,0.16]}\end{array}$ \\
\hline Coastal Tanna & $\begin{array}{c}0.07 \\
{[-0.11,0.26]}\end{array}$ & $\begin{array}{c}0.01 \\
{[-0.22,0.22]}\end{array}$ & $\begin{array}{c}0.03 \\
{[-0.20,0.26]}\end{array}$ \\
\hline Hadza & $\begin{array}{c}-0.26 \\
{[-0.50,-0.07]}\end{array}$ & $\begin{array}{c}-0.30 \\
{[-0.52,-0.11]}\end{array}$ & $\begin{array}{c}-0.32 \\
{[-0.60,-0.10]}\end{array}$ \\
\hline Inland Tanna & $\begin{array}{c}-0.07 \\
{[-0.27,0.11]}\end{array}$ & $\begin{array}{c}0.01 \\
{[-0.19,0.29]}\end{array}$ & $\begin{array}{c}-0.05 \\
{[-0.29,0.17]}\end{array}$ \\
\hline Lovu & $\begin{array}{c}0.09 \\
{[-0.08,0.27]}\end{array}$ & $\begin{array}{c}0.09 \\
{[-0.09,0.29]}\end{array}$ & $\begin{array}{c}0.10 \\
{[-0.09,0.31]}\end{array}$ \\
\hline Marajo & $\begin{array}{c}0.06 \\
{[-0.11,0.24]}\end{array}$ & $\begin{array}{c}0.09 \\
{[-0.10,0.29]}\end{array}$ & $\begin{array}{c}0.10 \\
{[-0.10,0.32]}\end{array}$ \\
\hline Mauritius & $\begin{array}{c}-0.02 \\
{[-0.20,0.16]}\end{array}$ & $\begin{array}{c}-0.04 \\
{[-0.23,0.15]}\end{array}$ & $\begin{array}{c}0.00 \\
{[-0.20,0.22]}\end{array}$ \\
\hline Tyva Republic & $\begin{array}{c}0.14 \\
{[-0.03,0.33]}\end{array}$ & $\begin{array}{c}0.15 \\
{[-0.04,0.34]}\end{array}$ & $\begin{array}{c}0.15 \\
{[-0.04,0.37]}\end{array}$ \\
\hline Coastal Tannav & $\begin{array}{c}-0.01 \\
{[-0.18,0.13]}\end{array}$ & $\begin{array}{c}0.09 \\
{[-0.06,0.32]}\end{array}$ & $\begin{array}{c}0.02 \\
{[-0.14,0.23]}\end{array}$ \\
\hline Hadzav & $\begin{array}{c}0.00 \\
{[-0.16,0.18]}\end{array}$ & $\begin{array}{c}0.08 \\
{[-0.06,0.28]}\end{array}$ & $\begin{array}{c}0.06 \\
{[-0.10,0.28]}\end{array}$ \\
\hline Inland Tannav & $\begin{array}{c}0.07 \\
{[-0.04,0.27]}\end{array}$ & $\begin{array}{c}-0.03 \\
{[-0.20,0.12]}\end{array}$ & $\begin{array}{c}0.02 \\
{[-0.14,0.20]}\end{array}$ \\
\hline Lovuv $^{v}$ & $\begin{array}{c}0.02 \\
{[-0.11,0.17]}\end{array}$ & $\begin{array}{c}-0.01 \\
{[-0.18,0.15]}\end{array}$ & $\begin{array}{c}-0.01 \\
{[-0.20,0.17]}\end{array}$ \\
\hline Marajov & $\begin{array}{c}-0.01 \\
{[-0.16,0.12]}\end{array}$ & $\begin{array}{c}-0.08 \\
{[-0.27,0.05]}\end{array}$ & $\begin{array}{c}-0.04 \\
{[-0.23,0.11]}\end{array}$ \\
\hline Mauritius ${ }^{v}$ & $\begin{array}{c}-0.07 \\
{[-0.25,0.04]}\end{array}$ & $\begin{array}{c}-0.05 \\
{[-0.23,0.08]}\end{array}$ & $\begin{array}{c}-0.06 \\
{[-0.27,0.07]}\end{array}$ \\
\hline Tyva Republic ${ }^{v}$ & $\begin{array}{c}0.00 \\
{[-0.14,0.15]}\end{array}$ & $\begin{array}{c}-0.01 \\
{[-0.17,0.13]}\end{array}$ & $\begin{array}{c}0.01 \\
{[-0.15,0.18]}\end{array}$ \\
\hline${ }^{v}$ Varied effect & g & o & g*o \\
\hline Model (R Script) & m1bin & m2bin & m3bin \\
\hline
\end{tabular}


Table S5 | Estimates and $\mathbf{9 5 \%}$ credibility intervals of estimates for distant ingroup fusion models. Varying effects for distant ingroup fusion are denoted with (c) and outgroup relations with an (o).

\begin{tabular}{|c|c|c|}
\hline & $\begin{array}{c}\beta \\
{[95 \% \mathrm{Cl}]}\end{array}$ & $\begin{array}{c}\beta \\
{[95 \% \mathrm{Cl}]}\end{array}$ \\
\hline Intercept & $\begin{array}{c}-0.19 \\
{[-0.37,-0.02]}\end{array}$ & $\begin{array}{c}-0.19 \\
{[-0.38,-0.00]}\end{array}$ \\
\hline Dist.* Outg. & $\begin{array}{c}-0.06 \\
{[-0.40,0.24]}\end{array}$ & -- \\
\hline Distant Fusion & $\begin{array}{c}0.04 \\
{[-0.09,0.17]}\end{array}$ & $\begin{array}{c}0.06 \\
{[-0.05,0.17]}\end{array}$ \\
\hline Outgroup Relations & $\begin{array}{c}0.11 \\
{[-0.17,0.38]}\end{array}$ & -- \\
\hline Treatment & -- & -- \\
\hline Game Order & -- & -- \\
\hline Coastal Tannese & $\begin{array}{c}0.14 \\
{[-0.06,0.37]}\end{array}$ & $\begin{array}{c}0.11 \\
{[-0.10,0.35]}\end{array}$ \\
\hline Hadza & $\begin{array}{c}-0.18 \\
{[-0.41,0.02]}\end{array}$ & $\begin{array}{c}-0.23 \\
{[-0.46,-0.01]}\end{array}$ \\
\hline Inland Tannese & $\begin{array}{c}0.00 \\
{[-0.20,0.20]}\end{array}$ & $\begin{array}{c}0.01 \\
{[-0.21,0.21]}\end{array}$ \\
\hline Indo-Fijians & $\begin{array}{c}0.12 \\
{[-0.07,0.32]}\end{array}$ & $\begin{array}{c}0.14 \\
{[-0.06,0.34]}\end{array}$ \\
\hline Marajó Brazilians & $\begin{array}{c}0.07 \\
{[-0.12,0.26]}\end{array}$ & $\begin{array}{c}0.10 \\
{[-0.11,0.30]}\end{array}$ \\
\hline Mauritians & $\begin{array}{c}-0.06 \\
{[-0.25,0.13]}\end{array}$ & $\begin{array}{c}-0.03 \\
{[-0.24,0.16]}\end{array}$ \\
\hline Tyvans & $\begin{array}{c}0.18 \\
{[-0.01,0.37]}\end{array}$ & $\begin{array}{c}0.19 \\
{[-0.01,0.39]}\end{array}$ \\
\hline Yasawan-Fijians & $\begin{array}{c}-0.28 \\
{[-0.52,-0.08]}\end{array}$ & $\begin{array}{c}-0.30 \\
{[-0.55,-0.09]}\end{array}$ \\
\hline Coastal Tannese $^{\mathrm{v}}$ & $\begin{array}{c}-0.06 \\
{[-0.45,0.25]}\end{array}$ & $\begin{array}{c}-0.04 \\
{[-0.24,0.07]}\end{array}$ \\
\hline Hadzav & $\begin{array}{c}-0.14 \\
{[-0.60,0.17]}\end{array}$ & $\begin{array}{c}-0.00 \\
{[-0.14,0.15]}\end{array}$ \\
\hline Inland Tannese ${ }^{v}$ & $\begin{array}{c}-0.01 \\
{[-0.43,0.31]}\end{array}$ & $\begin{array}{c}0.01 \\
{[-0.11,0.15]}\end{array}$ \\
\hline Indo-Fijians ${ }^{v}$ & $\begin{array}{c}0.02 \\
{[-0.25,0.31]}\end{array}$ & $\begin{array}{c}-0.00 \\
{[-0.14,0.12]}\end{array}$ \\
\hline Marajó Brazilians` & $\begin{array}{c}0.09 \\
{[-0.15,0.47]}\end{array}$ & $\begin{array}{c}0.02 \\
{[-0.10,0.18]}\end{array}$ \\
\hline Mauritians ${ }^{v}$ & $\begin{array}{c}0.08 \\
{[-0.18,0.42]}\end{array}$ & $\begin{array}{c}0.02 \\
{[-0.09,0.16]}\end{array}$ \\
\hline Tyvans ${ }^{v}$ & $\begin{array}{c}0.01 \\
{[-0.29,0.31]}\end{array}$ & $\begin{array}{c}0.00 \\
{[-0.12,0.13]}\end{array}$ \\
\hline Yasawa-Fijians $^{v}$ & $\begin{array}{c}0.03 \\
{[-0.44,0.61]}\end{array}$ & $\begin{array}{c}-0.00 \\
{[-0.18,0.19]}\end{array}$ \\
\hline $\begin{array}{r}\text { v } \text { Varied effect } \\
\text { Model (R script) }\end{array}$ & $\begin{array}{l}* \mathrm{o} \\
\mathrm{mc1}\end{array}$ & $\begin{array}{c}\mathrm{c} \\
\mathrm{mc2}\end{array}$ \\
\hline
\end{tabular}




\subsubsection{The Individualist Game in the Tyva Republic}

In the main text, we speculated that the Ingroup*Outgroup interaction may be clearer in a self vs. ingroup game dyad. In this dyad, rather than a geographically distant ingroup, participants would sacrifice coins to their local ingroup at a cost to themselves. As we noted, Tyvans $(n=81)$ played this game, dubbed the "Individualist Game" (Purzycki \& Kulundary, 2018). However, the fusion scores were not the focal component of the initial report. Here, we apply a version of the main model reported in the text to the Tyvan data (m1tyva) along with a version without the proposed interaction ( $\mathrm{m} 2$ tyva):

$$
\begin{aligned}
& y_{i} \sim \operatorname{Binomial}\left(30, p_{i}\right) \\
& \operatorname{logit}\left(p_{i}\right)=\alpha+b_{g}{ }^{*} g_{i}+b_{o}{ }^{*} o_{i}+b_{g o} g_{i}{ }^{*} o_{i} \text { (m1tyva) } \\
& \operatorname{logit}\left(p_{i}\right)=\alpha+b_{g}{ }^{*} g_{i}+b_{o}{ }^{*} o_{i} \quad \text { (m2tyva) } \\
& \alpha, b_{g}{ }^{*} g_{i}, b_{o}{ }^{*} o_{i}, b_{g o} g_{i}{ }^{*} o_{i} \sim \operatorname{Normal}(0,1)
\end{aligned}
$$

Here, $y_{i}$ denotes the allocations to Buddhist Tyvans in Kyzyl, $g$ denotes fusion with Buddhist Tyvans from Kyzyl, and $o$ denotes fusion with ethnic Russians from Ak Dovurak, a mining town in western Tyva. Again, we modelled effects monotonically. As this was a single site, we varied neither intercepts nor effects.

Table S6 | Estimates and 95\% credibility intervals of model defined above with sample from the Tyva Republic. Model names correspond to the code in the supplementary $\mathrm{R}$ script.

\begin{tabular}{rcc} 
& m1tyva & m2tyva \\
Intercept & 0.04 & 0.09 \\
& {$[-0.51,0.37]$} & {$[-0.28,0.31]$} \\
Outgroup & 0.02 & 0.05 \\
& {$[-0.61,0.79]$} & {$[-0.26,0.53]$} \\
Ingroup & -0.10 & -0.13 \\
& {$[-0.64,0.57]$} & {$[-0.35,0.12]$} \\
Outgroup * Ingroup & 0.04 & -- \\
\hline
\end{tabular}

Table S6 reports the output showing that the ingroup-outgroup interaction had no association with outcome in the games (m1tyva). Note, however, that ingroup fusion did predict withholding coins from the local group. Note, too, that Tyvans largely played fairly (if a little generous; mean allocations to the ingroup was $15.23, S D=2.88$ ), thus making it difficult to infer what similar effects would be like in contexts with greater general withholding. Other analyses of the Tyvan data are reported elsewhere, but the fusion measures were not a focus of those analyses (Purzycki \& Kulundary, 2018).

\section{Supplementary Frequentist Analyses}

In this section, we provide additional analyses using frequentist analytical techniques as a robustness check for the findings produced by our main Bayesian models. First, as a quasi- 
manipulation-check, we examined the correlation between ingroup and outgroup relations, assessing whether heightened ingroup fusion comes at the expense of decreased outgroup relations scores. Contrary to this prediction, we observed a moderate positive correlation between these two measures (Pearson's $r=0.28,95 \% \mathrm{Cl}=[0.21-0.35]$ ), suggesting that the pictorial measure may capture general sociality rather than relationship to specific groups. Despite this finding, $26 \%$ of our sample indicated maximum fusion with ingroup and simultaneously minimal fusion with outgroup whereas only $14 \%$ indicated general prosociality (maximum on both fusion measures, see Tab. S1). This result indicates that a sufficiently high number of participants reported the purported negative relationship, lending credibility to our subsequent analyses.

First, we analyzed the simple effects of ingroup and outgroup scores on allocations to distant ingroups, varying these effects across sites. These analyses revealed that an increase of one on the pictorial ingroup fusion measure was associated with an increase of $0.6 \%$ in the likelihood of allocating a coin to religious ingroups (instead to the self). That is, the increase from minimum to maximum levels of ingroup fusion was associated with a $3 \%$ increase in the likelihood of coin sacrifice. Similar results were obtained for the outgroup measure, where an increase of one was associated with $0.4 \%$ increase in the likelihood of allocating to distant ingroups. In addition to the aforementioned correlation, these results also suggest that, at least in our sites, the measure of fusion was not sensitive to targeted groups (ingroup vs. outgroup), and instead measured general prosociality. Indeed, the coefficients of both measures were positive (see Table S5, Models fg and fo).

However, it could be argued that our data were generated by two processes, which mask the purported effects of outgroup hostility. That is, the effects of outgroup hostility on extreme ingroup sacrifice can be observed only for participants reporting high levels of ingroup fusion and low levels of outgroup relations; whereas reporting a mixture of positive ingroup and outgroup scores leads to a small sacrifice corresponding to general prosociality. To investigate this proposition, we interacted ingroup and outgroup scores and assessed the effects of this interaction on coin allocations to religious ingroups. The raw data (ignoring within-site nesting) are displayed in Fig. S3. The surface plots reveal that the highest allocations were in the segment of maximal fusion with outgroups and minimal fusion with ingroups. On the contrary, the predicted region of interest (high ingroup and low outgroup scores) exhibited low mean allocations. However, recall that the raw data are misleading due to low number of participants in some of these extreme segments (see Tab. S1).

To investigate this matter more rigorously, we attempted to build a multi-level binomial model, varying the Ingroup*Outgroup interaction across sites. However, fitting this model in $\mathrm{R}$ (R Core Team, 2016) using the glmer function in the Ime4 package (Bates, Mächler, Bolker, \& Walker, 2015, p. 4) revealed poor convergence of this model, despite trying several optimizers. Hence, we were forced to divide our outgroup measure into simpler categories (1-2 = 0; 3-4 = 1; $5=2$ ) in order to reach convergence. This problem bolsters the utility of the Bayesian 
framework when analyzing multi-level data with effects varying across nesting factors. Also note that compared to the Bayesian models $\mathrm{m} 1 \mathrm{a}$ and $\mathrm{m} 1 \mathrm{~b}$, we treat the ingroup and outgroup measures as continuous in the frequentist analyses (instead of modelling them as monotonic effects).

The results of the interaction model suggest that the slope of ingroup fusion predicting allocations to religious ingroups is more positive for low levels of outgroup scores (see Table S7). However, as can be seen in Fig. S6, these differences are driven by participants reporting low ingroup fusion; the intercepts differ across the three levels of outgroup relations such that higher outgroup scores are associated with larger allocations to distant ethnic and religious ingroups (cf. Figure S5). In other words, for maximum levels of ingroup fusion, outgroup relations do not play a role because all participants tended to split the endowment impartially between themselves and distant ingroups (while the theory predicts highest allocations for low levels of outgroup relations). Instead, the difference in slopes was driven by participants who indicated low levels of both the ingroup and outgroup measures; such participants were the most selfish. For completeness, we also report the same analyses using fusion with distant ingroups rather than local ingroups in Table S5 (cf. Table S3).

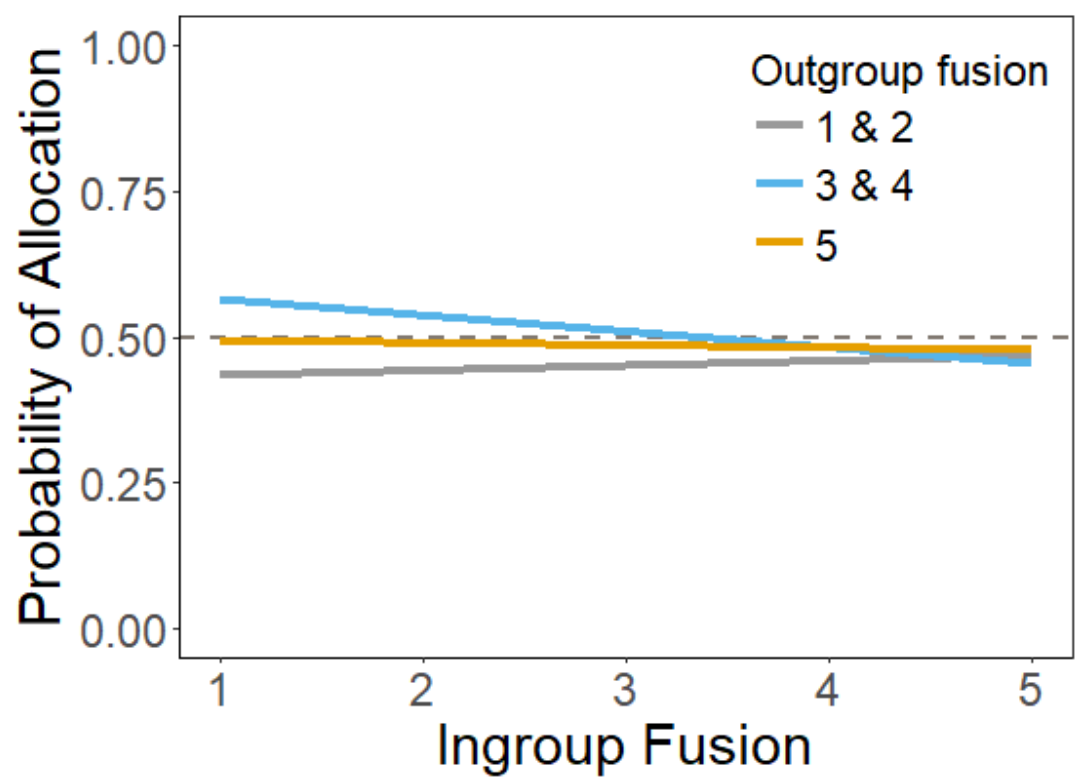

Figure S6 | Estimated regression lines from the multi-level binomial model across three levels of outgroup relations scores. While the slope of ingroup fusion when outgroup scores equal one or two is more positive compared to slopes across other levels of outgroup relations, this effect does not lead to larger amounts of sacrificed coins. Quite the contrary, maximal ingroup fusion led to impartial coin allocations across all levels of outgroup relations scores, indicating that the pictorial fusion measure assesses general prosociality. It is the lack of fusion with any group that drives the difference - such participants are more selfish. Note: the $y$-axis displays logistic transformations of the raw estimates to indicate probability of allocating a coin to religious ingroup. The dashed line indicates impartial allocations (half of endowment) to religious ingroups. 
Table S7 | Estimates and 95\% confidence intervals for frequentist models. Varying effects for ingroup fusion are denoted with (g) and outgroup with an (o). We also present models with distant fusion (c).

\begin{tabular}{|c|c|c|c|c|c|}
\hline & \multicolumn{3}{|c|}{ Ingroup models } & \multicolumn{2}{|c|}{ Distant models } \\
\hline & $\begin{array}{c}\beta \\
{[95 \% \mathrm{Cl}]}\end{array}$ & $\begin{array}{c}\beta \\
{[95 \% \mathrm{Cl}]}\end{array}$ & $\begin{array}{c}\beta \\
{[95 \% \mathrm{Cl}]}\end{array}$ & $\begin{array}{c}\beta \\
{[95 \% \mathrm{Cl}]}\end{array}$ & $\begin{array}{c}\beta \\
{[95 \% \mathrm{Cl}]}\end{array}$ \\
\hline Intercept & $\begin{array}{c}-0.25 \\
{[-0.44,-0.05]}\end{array}$ & $\begin{array}{c}-0.20 \\
{[-0.31,-0.08]}\end{array}$ & $\begin{array}{c}-0.30 \\
{[-0.49,-0.11]}\end{array}$ & $\begin{array}{c}-0.21 \\
{[-0.35,-0.06]}\end{array}$ & $\begin{array}{c}-0.27 \\
{[-0.50,-0.04]}\end{array}$ \\
\hline Ingroup/Distant & $\begin{array}{c}0.03 \\
{[-0.01,0.06]}\end{array}$ & $\begin{array}{l}-- \\
--\end{array}$ & $\begin{array}{c}0.04 \\
{[-0.001,0.07]}\end{array}$ & $\begin{array}{c}0.02 \\
{[-0.01,0.04]}\end{array}$ & $\begin{array}{c}0.03 \\
{[-0.01,0.06]}\end{array}$ \\
\hline Outgroup & -- & $\begin{array}{c}0.02 \\
{[-0.01,0.05]}\end{array}$ & -- & -- & $\begin{array}{l}-- \\
--\end{array}$ \\
\hline Outg. = 1 & $\begin{array}{l}-- \\
--\end{array}$ & $\begin{array}{l}-- \\
--\end{array}$ & $\begin{array}{c}0.67 \\
{[-0.04,1.39]}\end{array}$ & $\begin{array}{l}-- \\
--\end{array}$ & $\begin{array}{c}0.33 \\
{[0.20 ., 0.85]}\end{array}$ \\
\hline Outg. = 2 & -- & $\begin{array}{l}-- \\
--\end{array}$ & $\begin{array}{c}0.30 \\
{[-0.31,0.92]}\end{array}$ & -- & $\begin{array}{c}0.28 \\
{[-0.14,0.69]}\end{array}$ \\
\hline Ing./Dist.* Outg. = 1 & $\begin{array}{l}-- \\
--\end{array}$ & $\begin{array}{l}-- \\
--\end{array}$ & $\begin{array}{c}-0.15 \\
{[-0.30,0.01]}\end{array}$ & $\begin{array}{l}-- \\
--\end{array}$ & $\begin{array}{c}-0.06 \\
{[-0.19,0.06]}\end{array}$ \\
\hline Ing./Dist. *Outg. = 2 & $\begin{array}{l}-- \\
-- \\
\end{array}$ & $\begin{array}{l}-- \\
-- \\
\end{array}$ & $\begin{array}{c}-0.05 \\
{[-0.18,0.08]} \\
\end{array}$ & $\begin{array}{l}-- \\
-- \\
\end{array}$ & $\begin{array}{c}-0.05 \\
{[-0.15,0.05]} \\
\end{array}$ \\
\hline Coastal Tannese & -0.11 & -0.08 & -0.16 & -0.12 & -0.06 \\
\hline Hadza & -0.61 & -0.35 & -0.63 & -0.43 & -0.68 \\
\hline Inland Tannese & -0.24 & -0.18 & -0.30 & -0.19 & -0.24 \\
\hline Indo-Fijians & -0.06 & -0.09 & -0.15 & -0.07 & -0.06 \\
\hline Marajó Brazilians & -0.11 & -0.14 & -0.22 & -0.09 & -0.10 \\
\hline Mauritians & -0.29 & -0.24 & -0.34 & -0.23 & -0.29 \\
\hline Tyvans & 0.01 & -0.03 & -0.07 & -0.02 & 0.03 \\
\hline Yasawan-Fijians & -0.54 & -0.45 & -0.55 & -0.50 & -0.78 \\
\hline Coastal Tannese $^{v}$ & 0.01 & 0.01 & $0.51 / 0.12$ & -- & $0.08 / 0.02$ \\
\hline Hadzav & 0.05 & -0.01 & $1.07 / 0.75$ & -- & $0.81 / 0.78$ \\
\hline Inland Tannese ${ }^{v}$ & 0.03 & 0.02 & $0.67 / 0.28$ & -- & $0.29 / 0.24$ \\
\hline Indo-Fijians ${ }^{v}$ & 0.01 & 0.02 & $0.49 / 0.05$ & -- & $0.07 / 0.02$ \\
\hline Marajó Brazilians & 0.01 & 0.03 & $0.57 / 0.21$ & -- & $0.12 / 0.06$ \\
\hline Mauritians ${ }^{v}$ & 0.03 & 0.03 & $0.72 / 0.40$ & -- & $0.34 / 0.29$ \\
\hline Tyvans $^{v}$ & 0.01 & 0.03 & $0.39 /-0.02$ & -- & $-0.04 /-0.10$ \\
\hline Yasawa-Fijians $^{\vee}$ & 0.05 & 0.01 & $0.97 / 0.63$ & -- & $0.92 / 0.90$ \\
\hline${ }^{\vee}$ Varied effect & g & o & $g * o=1 / g * o=2$ & c & $c^{*} o=1 / c^{*} o=2$ \\
\hline Model (R script) & $\mathrm{fg}$ & fo & fgo & $\mathrm{fc}$ & fco \\
\hline
\end{tabular}

Note: Compared to Bayesian models (Table S2), the frequentist models do not display $95 \% \mathrm{Cl}$ for varying effects. Ingroup/Distant show coefficients for ingroup and distant fusion, respectively. The model fc does not contain site-specific intercepts due to convergence issues. 


\section{Supplementary Discussion}

In summary, these results suggest that lack of fusion with any group is generally associated with selfishness whereas increasing fusion with either outgroup or ingroup increases willingness to sacrifice coins for distant ingroups. In other words, the effect of outgroups appears to be additive rather than multiplicative. In our sample, the measure of outgroup relations worked as an indicator of general pro-group orientation. Nevertheless, these results are limited by two possibilities. First, it could be argued that the structure of the RAG, where impartial money allocation between oneself and religious ingroup is according to the rules of the game, capped possible extreme sacrificial behavior for the ingroup. Allocating more than half of one's endowment to religious ingroups would mean breaking the rules of the game, hence we could not observe extreme behaviors in the region of interest (maximal ingroup and minimal outgroup scores). On the other hand, the identity fusion literature often works with extremebut hypothetical-scenarios such as jumping from a bridge to stop a trolley with one's body; thus, breaking the rules in an anonymous game to sacrifice more coins for the ingroup perhaps should not be that difficult for highly fused participants; there is no a priori reason to discount subtler forms of sacrifice and the theory does not speak to this subtlety. Second, to avoid confounds, we avoided selected outgroups engaging in outright warfare with the ingroups, though intergroup relations definitely varied (e.g., the Hadza and Datoga have a long-standing feud and often violent confrontations while Catholic and Evangelical Brazilians have largely peaceable relations). While the effects of outgroup hostility should be observed even in situations that lack direct between-group conflict (groups still compete), intensified inter-group conflict might limit the extreme outgroup scores we found in our sample and motivate people to allocate more coins to ingroups.

\section{References}

Bates, D., Mächler, M., Bolker, B. M., \& Walker, S. C. (2015). Fitting linear mixed-effects models using Ime4. Journal of Statistical Software, 67(1), 1-48. https://doi.org/10.18637/jss.v067.i01

Bürkner, P.-C. (2017). brms: An R package for Bayesian multilevel models using Stan. Journal of Statistical Software, 80(1), 1-28.

Gómez, A., Brooks, M. L., Buhrmester, M. D., Vázquez, A., Jetten, J., \& Swann Jr, W. B. (2011). On the nature of identity fusion: insights into the construct and a new measure. Journal of Personality and Social Psychology, 100(5), 918.

Hamilton, W. D. D. (1964). The genetical evolution of social behaviour, I \& II. Journal of Theoretical Biology, 7(1), 1-52. https://doi.org/10.1016/0022-5193(64)90038-4

Hruschka, D., Efferson, C., Jiang, T., Falletta-Cowden, A., Sigurdsson, S., McNamara, R., ... Henrich, J. (2014). Impartial institutions, pathogen stress and the expanding social network. Human Nature, 25(4), 567-579. https://doi.org/10.1007/s12110-014-9217-0

Jiang, T. (2013). Cheating in mind games: The subtlety of rules matters. Journal of Economic Behavior \& Organization, 93, 328-336. https://doi.org/10.1016/j.jebo.2013.04.003 
Jong, J., Whitehouse, H., Kavanagh, C., \& Lane, J. (2015). Shared Negative Experiences Lead to Identity Fusion via Personal Reflection. PLOS ONE, 10(12), 1-12. https://doi.org/10.1371/journal.pone.0145611

Lang, M., Bahna, V., Shaver, J. H., Reddish, P., \& Xygalatas, D. (2017). Sync to link: Endorphinmediated synchrony effects on cooperation. Biological Psychology, 127, 191-197. https://doi.org/10.1016/j.biopsycho.2017.06.001

Lewandowski, D., Kurowicka, D., \& Joe, H. (2009). Generating random correlation matrices based on vines and extended onion method. Journal of Multivariate Analysis, 100(9), 1989-2001. https://doi.org/10.1016/j.jmva.2009.04.008

McElreath, R. (2018). Statistical Rethinking: A Bayesian Course with Examples in R and Stan. CRC Press.

Purzycki, B. G., Apicella, C., Atkinson, Q. D., Cohen, E., McNamara, R. A., Willard, A. K., ... Henrich, J. (2016a). Cross-cultural dataset for the evolution of religion and morality project. Scientific Data, 3, 160099. https://doi.org/10.1038/sdata.2016.99

Purzycki, B. G., Apicella, C., Atkinson, Q. D., Cohen, E., McNamara, R. A., Willard, A. K., ... Henrich, J. (2016b). Moralistic gods, supernatural punishment and the expansion of human sociality. Nature, 530(7590), 327-330. https://doi.org/10.1038/nature16980

Purzycki, B. G., Henrich, J., Apicella, C., Atkinson, Q. D., Baimel, A., Cohen, E., ... Norenzayan, A. (2018). The evolution of religion and morality: a synthesis of ethnographic and experimental evidence from eight societies. Religion, Brain \& Behavior, 8(2), 101-132. https://doi.org/10.1080/2153599X.2016.1267027

Purzycki, B. G., \& Kulundary, V. (2018). Buddhism, identity, and class: fairness and favoritism in the Tyva Republic. Religion, Brain \& Behavior, 8(2), 205-226. https://doi.org/10.1080/2153599X.2016.1267031

R Core Team. (2016). R: A language and environment for statistical computing. Vienna: $\mathrm{R}$ Foundation for Statistical Computing.

Schubert, T. W., \& Otten, S. (2002). Overlap of Self, Ingroup, and Outgroup: Pictorial Measures of Self-Categorization. Self and Identity, 1(4), 353-376. https://doi.org/10.1080/152988602760328012

Swann Jr., W. B., Gómez, Á., Conor, D., Francisco, J., \& Huici, C. (2009). Identity fusion: The interplay of personal and social identities in extreme group behavior. Journal of Personality and Social Psychology, 96(5), 995-1011. https://doi.org/10.1037/a0013668

Swann, W. B. (1983). Self-verification: Bringing social reality into harmony with the self. In Social Psychological Perspectives on the Self, Vol. 2 (pp. 33-66). Hilsdale, NJ: Erlbaum. https://doi.org/10.1126/science.218.4574.782

Swann, W. B., Buhrmester, M. D., Gómez, A., Jetten, J., Bastian, B., Vázquez, A., ... Zhang, A. (2014). What makes a group worth dying for? Identity fusion fosters perception of familial ties, promoting self-sacrifice. Journal of Personality and Social Psychology, 106(6), 912-926. https://doi.org/10.1037/a0036089

Swann, W. B., Gómez, Á., Buhrmester, M. D., López-Rodríguez, L., Jiménez, J., \& Vázquez, A. (2014). Contemplating the ultimate sacrifice: Identity fusion channels pro-group affect, cognition, and moral decision making. Journal of Personality and Social Psychology, 106(5), 713-727. https://doi.org/10.1037/a0035809 
Swann, W. B., Gómez, A., Dovidio, J. F., Hart, S., \& Jetten, J. (2010). Dying and killing for one's group: identity fusion moderates responses to intergroup versions of the trolley problem. Psychological Science, 21(8), 1176-1183. https://doi.org/10.1177/0956797610376656

Swann, W. B., Gómez, Á., Huici, C., Morales, J. F., \& Hixon, J. G. (2010). Identity Fusion and SelfSacrifice: Arousal as a Catalyst of Pro-Group Fighting, Dying, and Helping Behavior. Journal of Personality and Social Psychology, 99(5), 824-841. https://doi.org/10.1037/a0020014

Swann, W. B., Gómez, A., Seyle, D. C., Morales, J. F., \& Huici, C. (2009). Identity fusion: the interplay of personal and social identities in extreme group behavior. Journal of Personality and Social Psychology, 96(5), 995-1011. https://doi.org/10.1037/a0013668

Swann, W. B., \& Hill, C. A. (1982). When our identities are mistaken: Reaffirming selfconceptions through social interaction. Journal of Personality and Social Psychology, 43(1), 59-66. https://doi.org/10.1037/0022-3514.43.1.59

Swann, W. B., Jetten, J., Gómez, Á., Whitehouse, H., \& Bastian, B. (2012). When group membership gets personal: A theory of identity fusion. Psychological Review, 119(3), 441-456. https://doi.org/10.1037/a0028589

Trivers, R. L. (1971). The evolution of reciprocal altruism. The Quarterly Review of Biology, 46(1), 35-57. https://doi.org/10.1086/406755

Vázquez, A., Gómez, Á., Ordoñana, J. R., Swann, W. B., \& Whitehouse, H. (2017). Sharing genes fosters identity fusion and altruism. Self and Identity, 16(6), 684-702. https://doi.org/10.1080/15298868.2017.1296887

Whitehouse, H. (2018). Dying for the group : Towards a general theory of extreme self-sacrifice. https://doi.org/10.1017/S0140525X18000249

Whitehouse, H., Jong, J., Buhrmester, M. D., Gómez, Á., Bastian, B., Kavanagh, C. M., ... Gavrilets, S. (2017). The evolution of extreme cooperation via shared dysphoric experiences. Scientific Reports, 7, 44292. https://doi.org/10.1038/srep44292

Whitehouse, H., McQuinn, B., Buhrmester, M., \& Swann, B. W. (2014). Brothers in arms: Libyan revolutionaries bond like family. Proceedings of the National Academy of Sciences, (Early edition), 10-12. https://doi.org/10.1073/pnas.1416284111

Wickham, H. (2009). ggplot2: Elegant graphics for data analysis. Springer-Verlag New York. 